\title{
Photocatalytic aided removal of nitrogen oxides and VOCs from outdoor environment: graphene as a highway for electron mobility in $\mathrm{TiO}_{2}$ nanoparticles
}

\author{
DM Tobaldi, ${ }^{a,}$ D Dvoranová, ${ }^{b}$ L Lajaunie,${ }^{c, d}$ N Rozman, ${ }^{e}$ B Figueiredo, ${ }^{f}$ MP Seabra, ${ }^{a}$ A Sever Škapin,,${ }^{e} \mathrm{JJ}$ \\ Calvino, ${ }^{c, d}$ V Brezová, ${ }^{b}$ JA Labrincha ${ }^{a}$
}

${ }^{a}$ Department of Materials and Ceramic Engineering and CICECO-Aveiro Institute of Materials, University of Aveiro, Campus Universitário de Santiago, 3810-193 Aveiro, Portugal

${ }^{b}$ Institute of Physical Chemistry and Chemical Physics, Faculty of Chemical and Food Technology, Slovak University of Technology in Bratislava, Radlinského 9, Bratislava, SK-812 37, Slovak Republic

`Departamento de Ciencia de los Materiales e Ingeniería Metalúrgica y Química Inorgánica, Facultad de Ciencias, Universidad de Cádiz, Campus Río San Pedro S/N, Puerto Real 11510, Cádiz, Spain

${ }^{d}$ Instituto Universitario de Investigación de Microscopía Electrónica y Materiales (IMEYMAT), Facultad de Ciencias, Universidad de Cádiz, Campus Río San Pedro S/N, Puerto Real 11510, Cádiz, Spain

${ }^{e}$ Slovenian National Building and Civil Engineering Institute, Dimičeva 12, 1000 Ljubljana, Slovenia

${ }^{f}$ Graphenest, Lugar da Estação, Edifício Vouga Park, 3740-070 Paradela do Vouga, Portugal

*Corresponding author. Tel.: +351 234370041

E-mail addresses: david.tobaldi@ua.pt; david@davidtobaldi.org (DM Tobaldi)

Twitter: @D14MT (DM Tobaldi) 


\begin{abstract}
Outdoor and indoor air pollution has become a global concern in modern society. Although many policies and regulations on air quality have been promulgated worldwide over the past decades, airborne pollution still negatively affects health and therefore the life-style of human beings. One of the strategies to challenge this problem might be reducing the amount of airborne pollutant by mineralising them via photoinduced reactions. Photocatalytic oxidation of gaseous pollutants via titanium dioxide is one of the most investigated solar photochemical reactions. In this research work, by means of a green sol-gel procedure, we have coupled titania to graphene ( 0.5 and $1.0 \mathrm{wt} \%)$ aiming to increase the solar photocatalytic activity of the produced hybrid materials. The photocatalytic reactions were assessed by monitoring the removal of nitrogen oxides and two different volatile organic compounds (benzene and isopropanol). Our results highlight the exceptional characteristics of the $\mathrm{TiO}_{2} /$ graphene hybrid material (1.0 wt\% graphene), and its suitability for multi-purpose applications in the field of environmental remediation. Compared to unmodified titania, the hybrid material with $1.0 \mathrm{wt} \%$ graphene shows a clear enhancement in the photocatalytic removal of those hazardous pollutants - corresponding to more than twice the photocatalytic degradation rate. In addition, the same material is highly stable and shows fully recyclability over repeated tests. Hybrid titania-graphene materials could thus be exploited to grant a safer outdoor and indoor environments, having a beneficial impact on public health and thus on the quality of our lives.
\end{abstract}

Keywords: Air pollution; Volatile organic compounds; Nitrogen oxides; Graphene; Solar photochemical reaction. 


\section{Introduction}

Air pollution is defined by the World Health Organisation as: "contamination of the indoor or outdoor environment by any chemical, physical or biological agent that modifies the natural characteristics of the atmosphere" [1]. Seinfeld and Pandis proposed an extended definition, stating that: "air pollution is the presence in the air of one or more substances at a concentration or for duration above their natural levels, with the potential to produce an adverse effect" [2]. This implies that some of the substances that are regarded to be "air pollutant", are naturally present in the air [3]. Those air pollutants have both natural and anthropogenic origin. Indeed, anthropogenic activity has had, and is still having, a dominant role in the increase of air pollutants to levels that yield adverse impact on human health and on the environment. Indeed, exposure to air pollution has been reported to be as the $5^{\text {th }}$ ranking human health risk factor worldwide [4]. Several studies recognised an association amid air pollution carcinogenity [5,6], mortality $[7,8]$, as well as air pollution and the climate changes that we are idly witnessing [9].

Common (indoor and outdoor) anthropogenic air pollutants are: particulate matter (PM), nitrogen oxides $\left(\mathrm{NO}_{x}\right)$, and volatile organic compounds (VOCs). PM air pollution is given by a mixture of microscopic solid particles and liquid droplets. Those small particles are hazardous because they can be inhaled into the lungs. PM with an aerodynamic diameter of less than 10 micrometres is named $\mathrm{PM}_{10}$. Fine-particulate air pollution includes particles with an aerodynamic diameter equal to or below 2.5 micrometres $\left(\mathrm{PM}_{2.5}\right)$. Those particles $\left(\mathrm{PM}_{10}\right.$ and $\left.\mathrm{PM}_{2.5}\right)$ typically originate themselves from the combustion of fossil fuels in transportation, manufacturing, and power generation [10]. $\mathrm{NO}_{x}$ emissions come from the combustion processes in stationary and mobile units [11], thus they are commonly related to traffic-sources incidentally, around $80 \%$ of the $\mathrm{NO}_{x}$ emitted by automobiles comes from diesel-powered ones [12]. As such, $\mathrm{NO}_{x}$ are related to several short- and long-term health effects [13], even to carcinogenity [14]. VOCs are defined, according the directive from the European Union, as: "any organic compounds having at $293.15 \mathrm{~K}$ a vapour pressure of $0.01 \mathrm{KPa}$ or more, or having a corresponding volatility under the particular conditions of use". [15] Anthropogenic VOCs emission were estimated to be 142 Tg.C.yr ${ }^{-1}$ [16]. Moreover, ground-level ozone $\left(\mathrm{O}_{3}\right)$ is formed by photochemical reactions between sunlight and $\mathrm{NO}_{x}$ and VOCs [17], this again having an adverse impact on human health and climate. Additionally, those anthropogenic aerosols emissions are even able to (partly) obscure the sun, as it has been shown that up to $15 \%$ of photovoltaic electricity has been "lost" in China between 1960 and 2015 because of the increased air pollution [18]. However, in 2014, China introduced an ultra-low emissions standards policy to limit the emissions of those anthropogenic aerosols [19].

Given this context, it is imperative to strongly reduce this global threat. Indeed, renewable energies, as alternative sources of energy, are of utmost importance in this background - solar energy is achieving an increasingly important role. Photocatalysis is one of the most investigated solar (photo)reactions, as it has 
different levels of applications, ranging from water and air purification, hygiene and sanitation, environmental remediation, automotive industry [20]. The term photocatalysis defines the acceleration of a photoreaction by a material, the (photo)catalyst, that it is not consumed during said reaction [21]. Semiconductors are the materials used as (heterogeneous) photocatalyst. Amid those photocatalytic semiconductors, titanium dioxide (titania, $\mathrm{TiO}_{2}$ ), an Earth-abundant material, is one of the most promising candidates, as it possesses: high oxidising power and resistance to photocorrosion in water environment, non-toxicity, cost-effectiveness [22]. However, one of $\mathrm{TiO}_{2}$ 's drawback is the relative high recombination degree of the photogenerated exciton, dissipating the energy as light or heat, thus strongly affecting (negatively) the resulting photocatalytic activity [23]. Coupling/modifying $\mathrm{TiO}_{2}$ with other semiconductors, metals, noble-metals has been proposed to improve the spatial charge carrier separation, thus increasing the quantum yield of the photocatalytic process [24].

Sixteen years ago, Novoselov and Geim extracted from graphite a single layer of carbon atoms tightly packed into a two-dimensional honeycomb crystal structure [25]. This discovery led to the spark of the graphene-driven "gold rush", as the discoverers themselves dubbed graphene to be the "rising star on the horizon of materials science and condensed matter physics" [26]. Indeed, as for 2004, there has been remarkable progress in graphene research, quicker than that of any other material [27]. Graphene and titania can be combined [28], and their hybridisation results in a built-in electric field that increases the conductivity of that system by promoting interfacial charge transfer and separation [29]. That is: a decrease in the recombination rate of the photogenerated exciton (a critical step for a photocatalytic reaction), which in turn enhances the photocatalytic activity of the material.

In this paper, we have used a green sol-gel synthesis method to produce $\mathrm{TiO}_{2}$ and hybrid $\mathrm{TiO}_{2} /$ graphene nanostructures [30]. Their photocatalytic activity was assessed in gas phase, by monitoring the degradation of $\mathrm{NO}_{x}$ and two different types of VOCs, namely: benzene and isopropanol (2-propanol, IPA). Rubber and paint production plants, varnishes, households products are amongst the main sources of IPA [31]. The majority of IPA exposures are unintentional and relate with central nervous system and respiratory depression [32]. Benzene can be found primarily outdoor, due to traffic sources [33]. Toxicity of this VOC involves both bone marrow depression and leukemogenesis [34]. The light source used in the photocatalytic experiments imitated the solar spectrum, so to reproduce an outdoor environment. However, an artificial visible light emitting diode (LED) lamp - i.e. a lamp with no UV components, thus imitating and indoor environment was also used in the photocatalytic tests. Results showed that addition of graphene boosted titania's photocatalytic activity. With $1.0 \mathrm{wt} \%$ graphene and using a light imitating the solar spectrum, the photocatalytic activity of $\mathrm{TiO}_{2}$ was (more than) doubled in $\mathrm{NO}_{x}$ abatement, benzene removal, and IPA oxidation. Materials produced in this research work are therefore excellent candidates for offering a safer outdoor environment. 


\section{Experimental section}

\subsection{Sample preparation}

We followed an aqueous sol-gel procedure for the synthesis of $\mathrm{TiO}_{2}$-based photocatalytic materials; details of the synthesis can be found in a paper previously described by the authors [30]. Briefly, aqueous sols were made by means of the controlled hydrolysis and peptisation of titanium(IV)isopropoxide [Ti-i-pr, $\left.\mathrm{Ti}\left(\mathrm{OCH}\left(\mathrm{CH}_{3}\right)_{2}\right)_{4}\right]$ with Milli-Q water (18.2 M $\left.. \mathrm{cm}, \mathrm{H}_{2} \mathrm{O}: \mathrm{Ti}-i-\mathrm{pr}=4: 1\right)$ diluted in isopropyl alcohol (2-propanol, IPA). To do the graphene-modified $\mathrm{TiO}_{2}$ sols, 0.5 and $1.0 \mathrm{wt} \%$ of graphene nanoplatelets dispersed in ethanol (supplied by Graphenest) were added to the $\mathrm{TiO}_{2}$-based sol when this had $1 \mathrm{M}$ concentration. The sols were dried in an oven at $80^{\circ} \mathrm{C}$, and then the dried gels were thermally treated following thermal cycles reaching two maximum temperatures. (i) $250{ }^{\circ} \mathrm{C}$ with a heating rate of $15^{\circ} \mathrm{C} \cdot \mathrm{min}^{-1}$, pre-heating the furnace at $200{ }^{\circ} \mathrm{C}$, with a $8 \mathrm{~h}$ dwell time; (ii) $450^{\circ} \mathrm{C}$, with a heating rate of $5^{\circ} \mathrm{C} \cdot \mathrm{min}^{-1}$, with $2 \mathrm{~h}$ dwell time. Specimens were referred to as: $\mathbf{G} x / Y$ were $x$ stands for the graphene wt\% (0.5 or $1.0 \mathrm{wt} \%)$, and $Y$ is a number indicating the maximum temperature reached (i.e. 250 or $450{ }^{\circ} \mathrm{C}$ ). For instance, the $\mathrm{TiO}_{2}$ sol in which was added 0.5 wt $\%$ graphene, and thermally treated at $450{ }^{\circ} \mathrm{C} / 2 \mathrm{~h}$, will be referred to as: $\mathbf{G 0 . 5 / 4 5 0}$. Unmodified titania has been labelled: Ti250 or Ti450, according to the maximum temperature reached.

\subsection{Sample characterisation}

X-ray powder diffraction (XRPD) was used to reveal the mineralogical composition of the prepared specimens. The relative fractions of crystalline phases were determined via Rietveld refinements of the XRPD data. The XRPD patterns were collected at room temperature on a $\theta / \theta$ diffractometer (PANalytical X'Pert Pro, NL), equipped with a fast RTMS detector (PIXcel 1D, PANalytical), with Cu $K_{\alpha}$ radiation (45 kV and $40 \mathrm{~mA}, 20-80^{\circ} 2 \theta$ range, with a virtual step scan of $0.02{ }^{\circ} 2 \theta$, and virtual time per step of $200 \mathrm{~s}$ ). The Rietveld data analysis for obtaining semi-quantitative phase analysis (QPA) information was assessed using the GSAS-EXPGUI software packages $[35,36]$. The instrumental broadening was obtained from the refinement of $\mathrm{LaB}_{6}$ standard (NIST SRM 660 b) and included in all of the Rietveld refinements. The refinement strategy that we followed has been reported in previous a work [30]. XRPD was also used to gain microstructural information. At this purpose, the same instrument and setup as per the QPA was employed, but XRPD patterns were recorded in the $20-145^{\circ} 2 \theta$ range, with a virtual step-scan of $0.1^{\circ} 2 \theta$, and virtual time per step of $500 \mathrm{~s}$, so to work with data having a higher signal-to-noise ratio. The whole powder pattern modelling (WPPM) [37], as implemented in the PM2K software package [38], was used for the microstructural analysis of the diffraction data. In this work we adopted the same modelling approach as that described in previous works of us, assuming the crystalline domains to be spherical, and their diameter distributed according to a log-normal curve [30]. 
High-resolution scanning transmission electron microscopy (HR-TEM) imaging and electron energy-loss spectroscopy analysis (SR-EELS) were performed using a FEI Titan Cubed Themis microscope operated at 80 $\mathrm{kV}$. This microscope is equipped with a double Cs aberration-corrector, a monochromator, a X-FEG gun, an ultrahigh resolution energy filter (Gatan Quantum ERS), which allows working in dual-EELS mode, and a super X EDS detector. The monochromator was excited during imaging and spectroscopic experiments to minimize chromatic aberrations. Convergence and collection angles during EELS experiments were 5 and 21 mrad, respectively. The probe diameter for EELS acquisition was around $30 \mathrm{~nm}$. The energy resolution, measured as the full width at half maximum of the zero loss peak, was $0.75 \mathrm{eV}$ with a dispersion of 0.25 eV.pixel ${ }^{-1}$. Background subtraction for the core-loss spectra was performed by using the usual inverse power law function. Interpretations of the fast Fourier transform (FFT) patterns in HR-TEM images were performed by using the JEMS software [39].

Optical spectra of the prepared graphene- $\mathrm{TiO}_{2}$ hybrid materials were recorded on a Shimadzu UV-3100 spectrometer (JP), equipped with an integrating sphere, and a white reference material made of Spectralon; UV-vis spectral range was explored (250-850 nm), using 0.2 nm in resolution. Raman spectra were acquired on a RFS 100/S (Bruker, DE) equipped with a 1,064 nm Nd:YAG laser as the excitation source, in the $50-1,800 \mathrm{~cm}^{-1}$ wavenumber range, with $2 \mathrm{~cm}^{-1}$ in resolution. Specific surface area (SSA) of the specimens was measured by means of the Brunauer-Emmett-Teller (BET) method (Micromeritics Gemini 2380 , US) by means of $\mathrm{N}_{2}$ as the adsorbate gas, on samples degassed at $120^{\circ} \mathrm{C}$.

EPR spin trapping experiments were performed using the spin trapping agent 5,5-dimethyl-1-pyrroline $N$ oxide (DMPO; Sigma-Aldrich, distilled prior to the application). Benzene (anhydrous, 99.8\%) and 2-propanol (IPA, puriss. p.a., ACS reagent, $\geq 99.8 \%$ ) were purchased from Sigma-Aldrich. The DMPO solutions in benzene and IPA (0.2 M) were used to impregnate the powdered photocatalysts placed in a thin-walled quartz Q-band EPR tube (Bruker). As-prepared photocatalyst was mixed by a gentle stream of argon in order to reduce the concentration of dissolved oxygen, and to eliminate the EPR line broadening in benzene and IPA caused by oxygen dissolved in these solvents [40]. The sample was directly irradiated in the cavity of EPR spectrometer EMX (Bruker) operating at $100 \mathrm{kHz}$ field modulation in the standard $\mathrm{TE}_{102}$ rectangular cavity (ER $4102 \mathrm{ST}$, Bruker) at room temperature. An UV radiator [ $\lambda_{\max }=365 \mathrm{~nm}$; Bluepoint LED, Hönle UV Technology; irradiance of $15 \mathrm{~mW} . \mathrm{cm}^{-2}$ within the EPR cavity determined by a UVX radiometer (UVP, USA)] was used as irradiation source. The standard EPR spectrometer settings were as follows: microwave frequency: $\sim 9.447 \mathrm{GHz}$; microwave power: $11.5 \mathrm{~mW}$; center field: $363 \mathrm{mT}$; gain: $1 \times 10^{5}$; modulation amplitude: $0.05 \mathrm{mT}$; sweep time: $25 \mathrm{~s}$; time constant: $10.24 \mathrm{~ms}$; number of scans: 10 . The experimental EPR spectra were analysed by the WinEPR software (Bruker), and the simulated spectra were calculated with the EasySpin toolbox working under Matlab (MathWorks) software [41]. 


\subsection{Functional properties: photocatalytic experiments}

De-NO $x$ and benzene removal gas-solid phase photocatalytic experiments were carried out in the same reactor, that operated in continuous [42]. It comprised a cylindrical chamber (3.8 L internal volume) built from a high grade stainless steel with a stainless steel top with a sealed glass window to allow the light to reach the sample that was placed inside. A light imitating the solar spectrum (Osram Ultra-Vitalux, $300 \mathrm{~W}$ ) was used as light source. This was positioned $33 \mathrm{~cm}$ above the photocatalyst; the radiant flux per unit area (irradiance) reaching the surface of the photocatalyst was then equal to $3.5 \mathrm{~mW} . \mathrm{cm}^{-2}$ in the UV-A range, and $35 \mathrm{~mW} . \mathrm{cm}^{-2}$ in the visible spectral range - values measured with a radiometer (Delta OHM, HD2302.0, IT). A LED lamp (Philips warm white, $2700 \mathrm{~K}$ LED bulb, $9.5 \mathrm{~W}$ ) was employed to mimic an indoor environment. The LED was placed $12 \mathrm{~cm}$ above the photocatalyst. The irradiance reaching the photocatalyst was estimated to be approximately $5.8 \mathrm{~mW} \cdot \mathrm{cm}^{-2}$ in the visible-light range and nil in the UV-A range. Emission spectra of the solar and visible-light LED lamps are displayed in Figure S1 of the supplementary information file.

A Petri dish having $6 \mathrm{~cm}$ in diameter was filled up with a layer of photocatalyst $(0.10 \mathrm{~g})$. The tests were assessed at $24 \pm 1{ }^{\circ} \mathrm{C}$ (temperature inside the reactor) with a relative humidity of $36 \%$. These parameters were controlled by means of a thermocouple that was placed inside the chamber, and a humidity sensor placed in the inlet pipe, and they were stable throughout the tests.

As per the de- $\mathrm{NO}_{x}$ photocatalytic experiments, the initial concentration of $\mathrm{NO}_{x}$ (prepared using synthetic air and $\mathrm{NO}_{x}$ gas) was set at $200 \mathrm{ppb}$. That concentration is higher than that commonly reported outdoor, e.g. outdoor urban levels have an annual mean range of 11-48 ppb (around 20-90 $\mu \mathrm{g} \cdot \mathrm{m}^{-3}$ ) [43]. However, the safety limit of $200 \mu \mathrm{g} \cdot \mathrm{m}^{-3}$ (approximately $110 \mathrm{ppb}$ ) on a daily basis is often breached in many European Countries [44].

The outlet concentration of $\mathrm{NO}_{x}$ gases was measured using a chemiluminescence analyser (AC-31 $\mathrm{M}$, Environment SA, FR), according to a procedure that we described in very detail previously $[45,46]$.

When benzene was used as model gas, its concentration exiting through the outlet was measured using a VOC-72M gas analyser (Environment SA, FR), that is based on gas chromatography and photoionisation detector. The inlet gas mixture (prepared mixing gas cylinders containing synthetic air and benzene) was allowed to flow into the chamber until it stabilised at a concentration of $\sim 260 \mu \mathrm{g} \cdot \mathrm{m}^{-3}$ ( $\left.\sim 80 \mathrm{ppb}\right)$. This concentration was chosen because the World Health Organisation recommends an exposure to total VOCs $<300 \mu \mathrm{g} \cdot \mathrm{m}^{-3}$ during $8 \mathrm{~h} /$ day [47]. The mixture of air with that concentration of benzene was guaranteed using two mass flow controllers with a flow rate of $150 \mathrm{~mL} \cdot \mathrm{min}^{-1}$. The photocatalytic experiments were assessed by placing the photocatalyst inside the reactor and covering the glass window. Once the desired $\mathrm{NO}_{x}$ /benzene concentration was reached and it attained stable level into the reactor, the window glass was uncovered, the lamp turned on, and the photocatalytic reaction started. Photocatalytic activity for de- $\mathrm{NO}_{x}$ abatement and benzene removal was reported as formal quantum efficiency (FQE) [48], defined as the 
number of molecules degraded per incident photon. In this work, based on the results obtained in Section 3.2 in which the optical band-gap was determined, we presumed that prepared photocatalysts exploited the UV-A part of the electromagnetic spectrum (i.e. 315-400 nm) for band-to-band excitation, thus excluding wavelengths $>400 \mathrm{~nm}$. Furthermore, aiming to have a better comparison between the tested specimens, data relative to the first $2 \mathrm{~min}\left(\mathrm{de}-\mathrm{NO}_{x}\right)$ or $60 \mathrm{~min}$ (benzene removal) of reaction time, were interpreted according to a first-order kinetic law.

A different reactor was employed for the gas-phase oxidation of IPA and, unlike the reactor described previously, this was a batch system. It was a cylindrical reactor (1.4 $\mathrm{L}$ in volume) covered by a quartz glass connected by Teflon tubes to a FT-IR spectrometer; the whole batch system was hermetically sealed. IPA photocatalytic oxidation is as follows: IPA $\stackrel{k_{1}}{\rightarrow}$ acetone $\stackrel{k_{2}}{\rightarrow}$ further products $\rightarrow \mathrm{CO}_{2}+\mathrm{H}_{2} \mathrm{O}$. Following the works of Munuera and co-authors $[49,50]$, the IPA to acetone reaction is described as a zero order reaction, whilst the second reaction (acetone to further products) is a first order reaction. Also, Larson et al. [51], demonstrated that $k_{1} \gg k_{2}$, therefore, we can genuinely assume the initial reaction rate of acetone formation to be reasonably approximated as linear, and obtain a reliable kinetic for the photocatalytic activity. The working distance between the Petri dish and the lamp was $6 \mathrm{~cm}$. The light source employed for the photocatalytic tests was a $300 \mathrm{~W}$ Xenon lamp (Newport Oriel Instruments, US). The lamp imitates the solar light spectrum, both in the UV and visible range, with an irradiance of approximately $0.8 \mathrm{~mW} . \mathrm{cm}^{-2}$ in the UV range $(250-400 \mathrm{~nm})$, and $8.8 \mathrm{~mW} . \mathrm{cm}^{-2}$ in the wavelength range of $400-800 \mathrm{~nm}$. A $400 \mathrm{~nm}$ cut-off filter was used to exclude the UV radiation, and thus measurements were also taken only under visible-light irradiation. The filter decreases the light intensity, which reaches a value of $6.5 \mathrm{~mW} . \mathrm{cm}^{-2}$ in the $400-800$ $\mathrm{nm}$ range. Samples used in these tests were prepared following the same protocol as that used in the de$\mathrm{NO}_{x}$ and benzene removal photocatalytic tests. The relative humidity in the reacting system was kept constant in the range $25 \%-30 \%$ by means of a flow of air passing through molecular sieves until a predefined humidity was attained. Each experiment was performed by injecting $8 \mu \mathrm{L}$ of IPA ( $800 \mathrm{ppm}$ in gas phase) into the reacting system through a septum; the total reaction time was set at $24 \mathrm{~h}$, and the lamp was turned on after a certain period of time after IPA injection, to allow for an adsorption/desorption equilibrium. IPA degradation, as well as the acetone formation-degradation process, was followed by monitoring the calculated area of their characteristic peaks located at 1,104 and 1,207 $\mathrm{cm}^{-1}$, respectively, by using a FT-IR spectrometer (Perkin Elmer Spectrum BX, US). The acetone formation kinetics was taken as a measurement of photocatalytic activity, because the photocatalytic oxidation of IPA is the only source of acetone. Thus, although an indirect evidence, it unequivocally proves IPA oxidation. On the other hand, the decreasing concentration of IPA may be due to photocatalytic activity and some other undesired processes, like adsorption and possible minor leaking. [It has to be stressed here that the radiant fluxes (in the UV-A and visible regions) entering the reactors are significantly lower than those of xenon arc lamps that are normally used by the catalytic community - i.e. in the order of around $8 \mathrm{~mW} . \mathrm{cm}^{-2}$ in the UV-A region, and 
$80 \mathrm{~mW} . \mathrm{cm}^{-2}$ in the visible range [52-54]] All of the photocatalytic tests were repeated in triplicate to check recyclability and photostability of the photocatalysts.

\section{Results and discussion}

\subsection{XRPD and HR-TEM analyses}

XRPD patterns of the synthesised materials are shown in Figure S2a,b whilst Rietveld QPA results are listed in Table S1. A graphical output of a Rietveld refinement is in Figure $\mathrm{S}_{3} . \mathrm{TiO}_{2}$ thermally treated at $250{ }^{\circ} \mathrm{C} / 8 \mathrm{~h}$ (Ti250) is composed of anatase (79.6 wt\%), rutile (8.1 wt\%), and brookite (12.3 wt\%). Addition of graphene to the system strongly delayed the anatase-to-rutile phase transition (ART), being the anatase wt\% amount in G0.5/250 (G1.0/250): 94.2 wt\% (92.8 wt\%); that of rutile was: 0.6 wt\% (0.4 wt\%); brookite: 5.2 wt\% (6.7 wt\%). Similarly, graphene addition retarded the ART in the specimens thermally treated at $450{ }^{\circ} \mathrm{C} / 2 \mathrm{~h}$. Ti450 is composed of 70.8 wt\% anatase, 19.5 wt\% rutile, and 9.7 wt\% brookite. Specimens $\mathbf{~ G 0 . 5 / 4 5 0}$ (G1.0/450) are composed of: 89.1 wt\% (88.4 wt\%) anatase; rutile: 8.1 wt\% (9.4 wt\%); brookite: 2.8 wt\% (2.1 $w t \%)$. As per the microstructure, microstructural information as extracted from the WPPM formalism is listed in Table S2, and Figure S4 (an output of a WPPM modelling is shown in Figure S5). Consistent with QPA data, graphene addition to the system delayed the nucleation-and-growth of anatase crystalline domains - ART being a nucleation-and-growth phenomenon [55]. Indeed, the diameter of anatase crystalline domains in Ti250 is $4.4 \mathrm{~nm}$. That in $\mathbf{G 0 . 5 / 2 5 0 ~ ( G 1 . 0 / 2 5 0 ) ~ i s ~ e q u a l ~ t o : ~} 3.8 \mathrm{~nm}(3.9 \mathrm{~nm})$. A similar behaviour happens when the specimens are thermally treated at $450{ }^{\circ} \mathrm{C} / 2 \mathrm{~h}$ : the average diameter of anatase crystalline domain in Ti450 is $10.4 \mathrm{~nm}$. That in $\mathbf{G 0 . 5 / 4 5 0 ~ ( G 1 . 0 / 4 5 0 ) ~ i s : ~} 7.0 \mathrm{~nm}(6.2 \mathrm{~nm})$. Rutile nanocrystals in Ti450 have diameter equal to $14.4 \mathrm{~nm}$; those in $\mathbf{G 0 . 5 / 4 5 0 ~ ( G 1 . 0 / 4 5 0 ) : ~} 8.7 \mathrm{~nm}(8.3 \mathrm{~nm})-c f$ Table S2. 

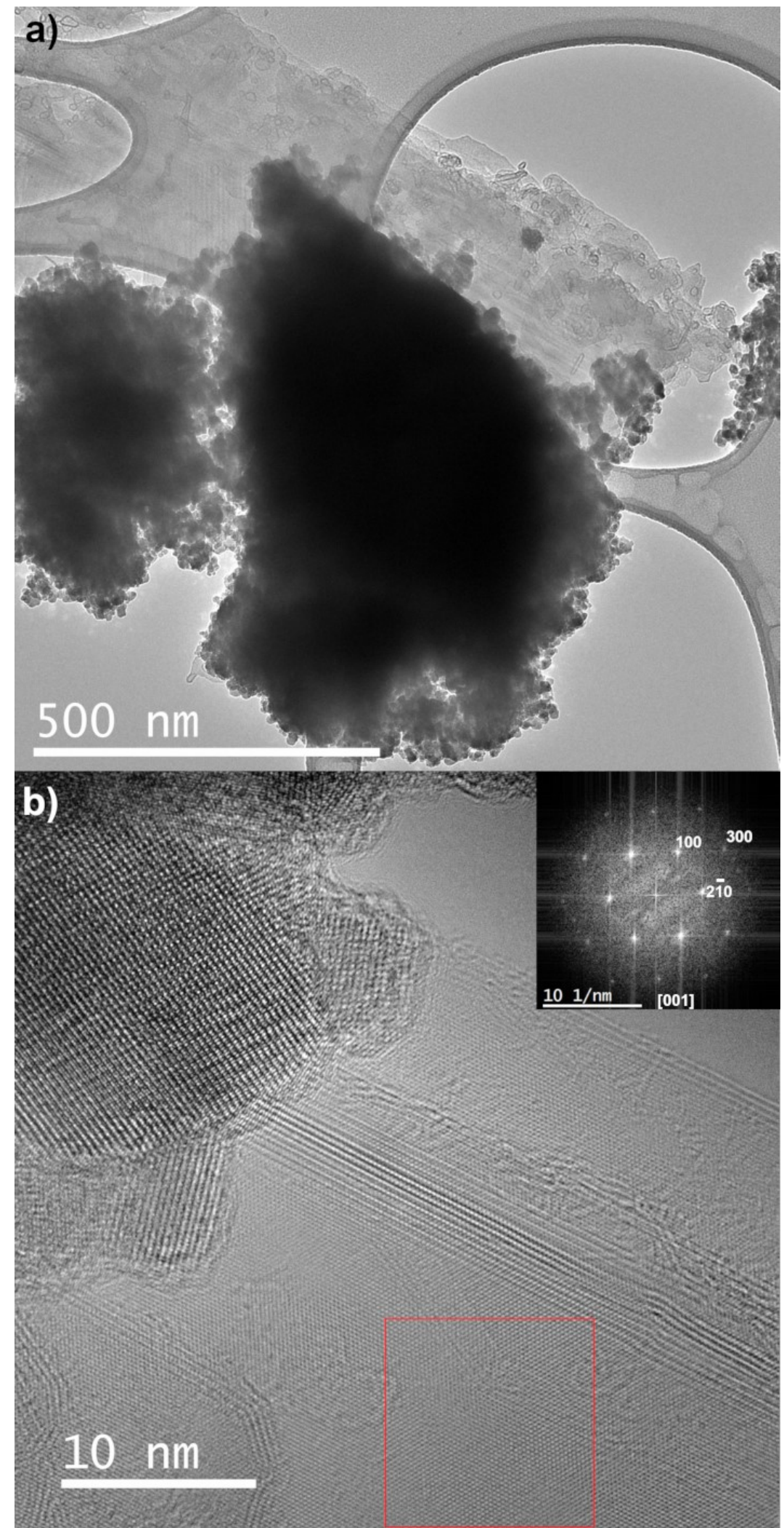

Figure 1. a) TEM image acquired on the sample G1.0/450. b) HR-TEM image acquired on the sample G1.0/450. The inset shows the FFT calculated on the area highlighted by the red square.

Figure 1a shows a TEM image acquired on the sample G1.0/450. The presence of nanoparticles and flakes in the same area can clearly be highlighted. The flakes have a typical size of about $500 \times 1000 \mathrm{~nm}$. Figure $1 \mathrm{~b}$ depicts an image of higher magnification taken in the same area. The high crystalline quality of both the 
nanoparticles and the flake can be clearly highlighted. The nanoparticles have a typical size of about 5-7 $\mathrm{nm}$. In addition, it should be noted that most of the flakes are constituted by 3 layers of graphene. Automatic indexation of the FFT pattern acquired on the flake show that this corresponds to a graphitic basal plane described in the [001] zone axis.

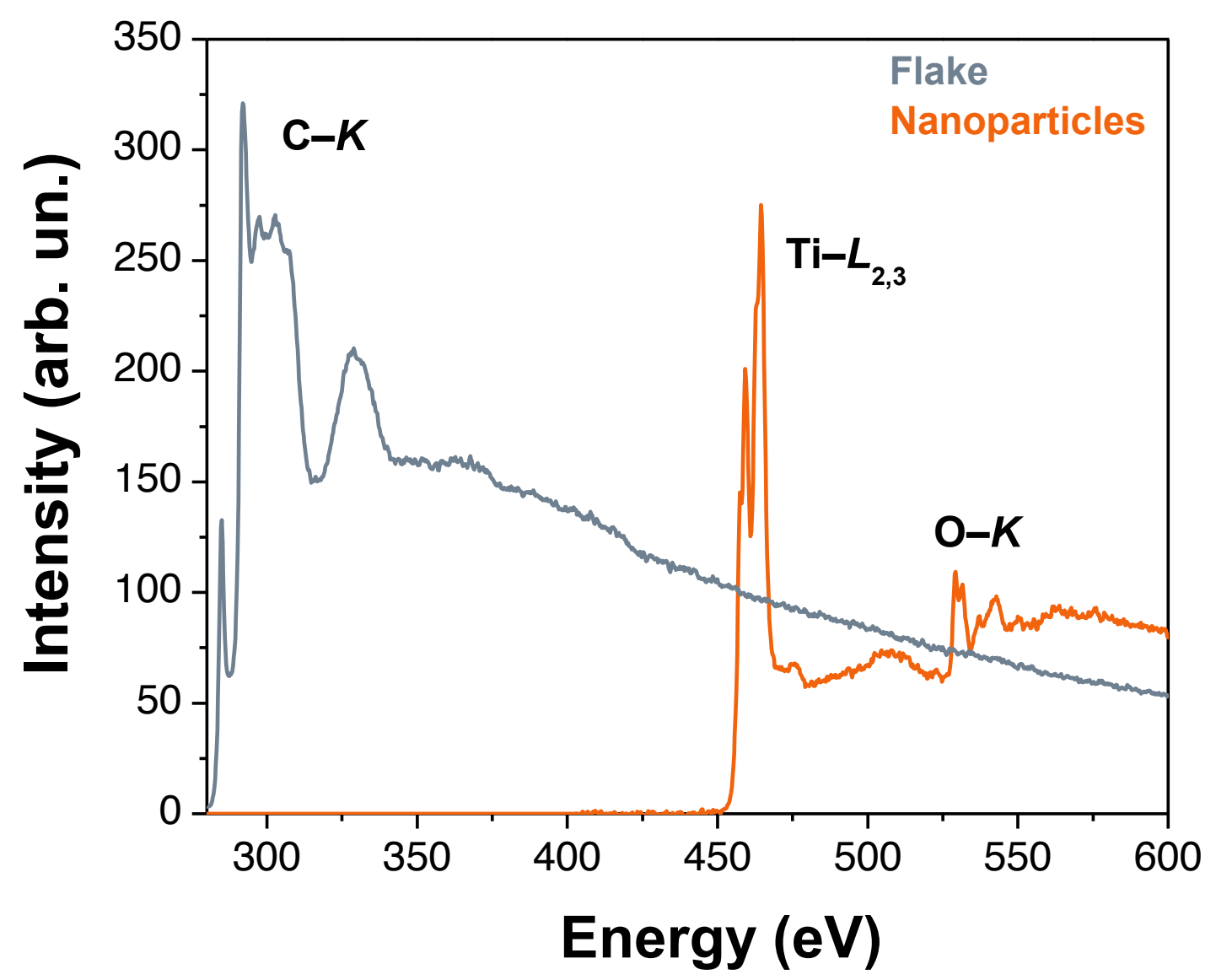

Figure 2. EELS spectra acquired on nanoparticles (orange curve) and one flake (dark blue curve) in G1.0/450.

To get insight on the chemical nature of the nanostructures, EELS spectra were acquired on the flakes and nanoparticles of G1.0/450 (Figure 2). The EELS spectrum acquired on the nanoparticles shows the presence of $\mathrm{Ti}-L_{2,3}$ and $\mathrm{O}-K$ edges located around 457 and $530 \mathrm{eV}$, respectively. On the other hand, the spectrum acquired on the flake shows only the presence of the $C-K$ edge around $285 \mathrm{eV}$. It should be noted that no other edges, related in particular to oxygen or nitrogen, can be highlighted on the probed energy range. In addition, the $\mathrm{C}-\mathrm{K}$ edge clearly shows fine-structure characteristics of a highly graphitic carbon. These results show that the hybrid nanostructure is constituted of few-layers of graphene mixed with small $\mathrm{TiO}_{2}$ 
nanoparticles [56]. Similar results concerning imaging and spectroscopic analyses were obtained on G1.0/250.

\subsection{UV-Vis and Raman spectroscopy}

Diffuse reflectance (DR) spectra are shown in Figure 3a,b. They all display one single absorption edge, located at around $380 \mathrm{~nm}$, and assigned to the band-to-band transition in titania [57]. Addition of graphene increased the absorption in the visible range, consistent with previous literature reports [58]. Values of the apparent optical bandgap energy $\left(E_{\mathrm{g}}\right)$ of the specimens are listed in Table 1 . These were extracted from the DR spectra by means of the Tauc-plot (considering direct and indirect interband transitions) [59], and of the differential reflectance method (Figure S6) [60]. Specimens are mostly composed of anatase (cf Table S1), and this $\mathrm{TiO}_{2}$ polymorph is commonly reported to have an indirect band-to-band transition [61]. However, the $E_{\mathrm{g}}$ values determined via the Tauc procedure, and assuming an indirect model, are in contrast with the expected $E_{\mathrm{g}}$ value of anatase (i.e. $\sim 3.2 \mathrm{eV} ; \sim 388 \mathrm{~nm}$ ) [62]. Therefore, a direct model for interband transition would seem more appropriate in this system [see also references $[46,63]]$ - indeed, although unusual, anatase having direct gap transition has already been reported in the literature $[64,65]$. 


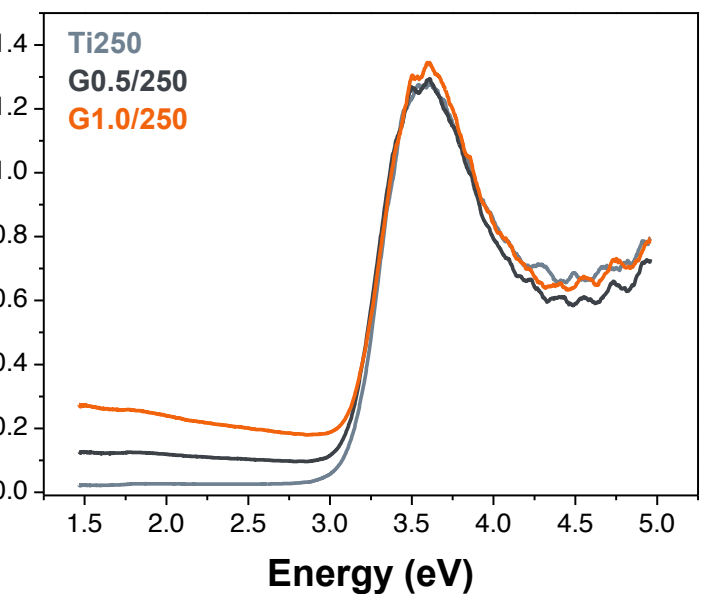

a)

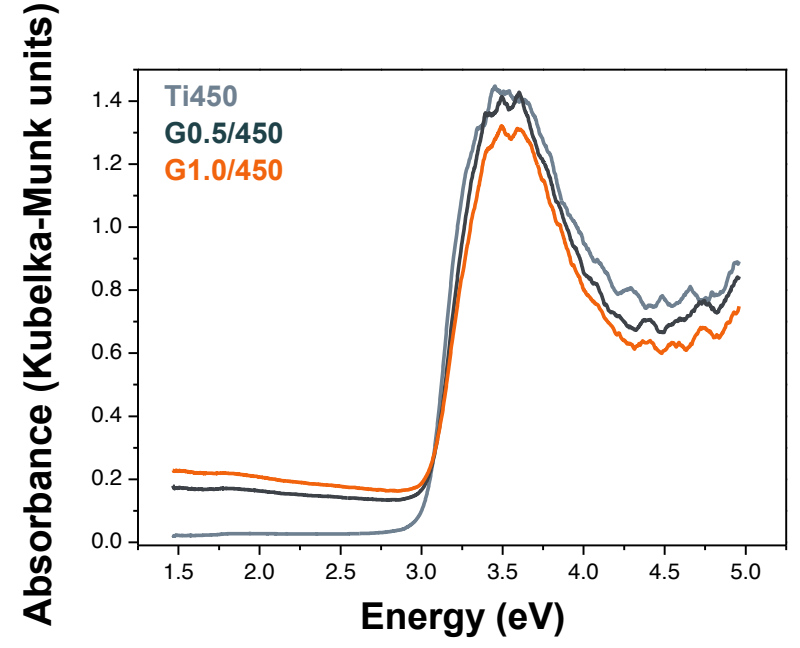

b)

Figure 3. Optical spectra (pseudo-absorption versus energy), as derived by Kubelka-Munk analysis of the DR spectra. a) Specimens thermally treated at $250^{\circ} \mathrm{C} / 8 \mathrm{~h}$; b) specimens thermally treated at $450{ }^{\circ} \mathrm{C} / 2 \mathrm{~h}$.

Table 1. Apparent optical $E_{\mathrm{g}}$, estimated according to the Tauc procedure and the differential reflectance method $(\mathrm{d} R / \mathrm{d} \lambda)$; BET specific surface area.

\begin{tabular}{|c|c|c|c|c|c|c|c|c|c|c|c|}
\hline \multirow{4}{*}{ Sample } & \multicolumn{10}{|c|}{ Apparent optical $E_{\mathrm{g}}$} & \multirow{4}{*}{$\begin{array}{l}S S A_{\mathrm{BET}} \\
\mathrm{m}^{2} \cdot \mathrm{g}^{-1}\end{array}$} \\
\hline & \multicolumn{4}{|c|}{ Tauc plot ${ }^{\dagger}$} & \multicolumn{6}{|c|}{$\mathrm{d} R / \mathrm{d} \lambda$} & \\
\hline & \multicolumn{2}{|c|}{ direct } & \multicolumn{2}{|c|}{ indirect } & \multicolumn{2}{|c|}{ anatase } & \multicolumn{2}{|c|}{ rutile } & \multicolumn{2}{|c|}{ brookite } & \\
\hline & eV & $\mathrm{nm}$ & $\mathrm{eV}$ & $\mathrm{nm}$ & $\mathrm{eV}$ & $\mathrm{nm}$ & eV & $\mathrm{nm}$ & eV & $\mathrm{nm}$ & \\
\hline $\mathrm{Ti250} / 8 \mathrm{~h}$ & 3.25 & 382 & 3.00 & 414 & 3.28 & 378 & 3.16 & 392 & 3.41 & 363 & $134.4 \pm 2.1$ \\
\hline G0.5/250 & 3.22 & 385 & 2.96 & 418 & 3.23 & 384 & - & - & - & - & $139.1 \pm 1.3$ \\
\hline G1.0/250 & 3.24 & 382 & 2.95 & 421 & 3.22 & 384 & - & - & - & - & $140.6 \pm 1.3$ \\
\hline Ti450 & 3.12 & 398 & 2.93 & 423 & 3.30 & 376 & 3.07 & 404 & 3.41 & 364 & $45.9 \pm 0.7$ \\
\hline G0.5/450 & 3.15 & 394 & 2.92 & 424 & 3.32 & 373 & 3.08 & 403 & - & - & $50.1 \pm 0.6$ \\
\hline G1.0/450 & 3.15 & 393 & 2.90 & 428 & 3.34 & 372 & 3.13 & 397 & - & - & $57.4 \pm 0.6$ \\
\hline
\end{tabular}

${ }^{\dagger}$ The absolute error in the Tauc-plot measurements was $<1 \%$.

However, the differential reflectance method has been reported to be a more reliable technique for extracting the $E_{\mathrm{g}}$ values in the $\mathrm{TiO}_{2}$ polymorphs system $[30,60,66]$. Indeed, values listed in Table 1 (6th to 11th columns), are consistent with anatase, rutile and brookite $E_{\mathrm{g}} \mathrm{s}$ reported in the literature $[62,67]$.

Raman spectra are displayed in Figure 4a,b. In this figure, the main Raman active mode of anatase are clearly detectable [i.e.: $E_{\mathrm{g}(1)}\left(144 \mathrm{~cm}^{-1}\right) ; B_{1 \mathrm{~g}(1)}\left(399 \mathrm{~cm}^{-1}\right) ; A_{1 \mathrm{~g},} B_{1 \mathrm{~g}(2)}\left(515 \mathrm{~cm}^{-1}\right) ; E_{\mathrm{g}(2)}\left(638 \mathrm{~cm}^{-1}\right)$ ] [68]. The major Raman bands assigned to graphene (i.e.: $D, G$, and a very weak $D^{\prime}$ ) [69], are identified in the specimens modified with graphene (see the inset in Figure $4 a, b$ ). 

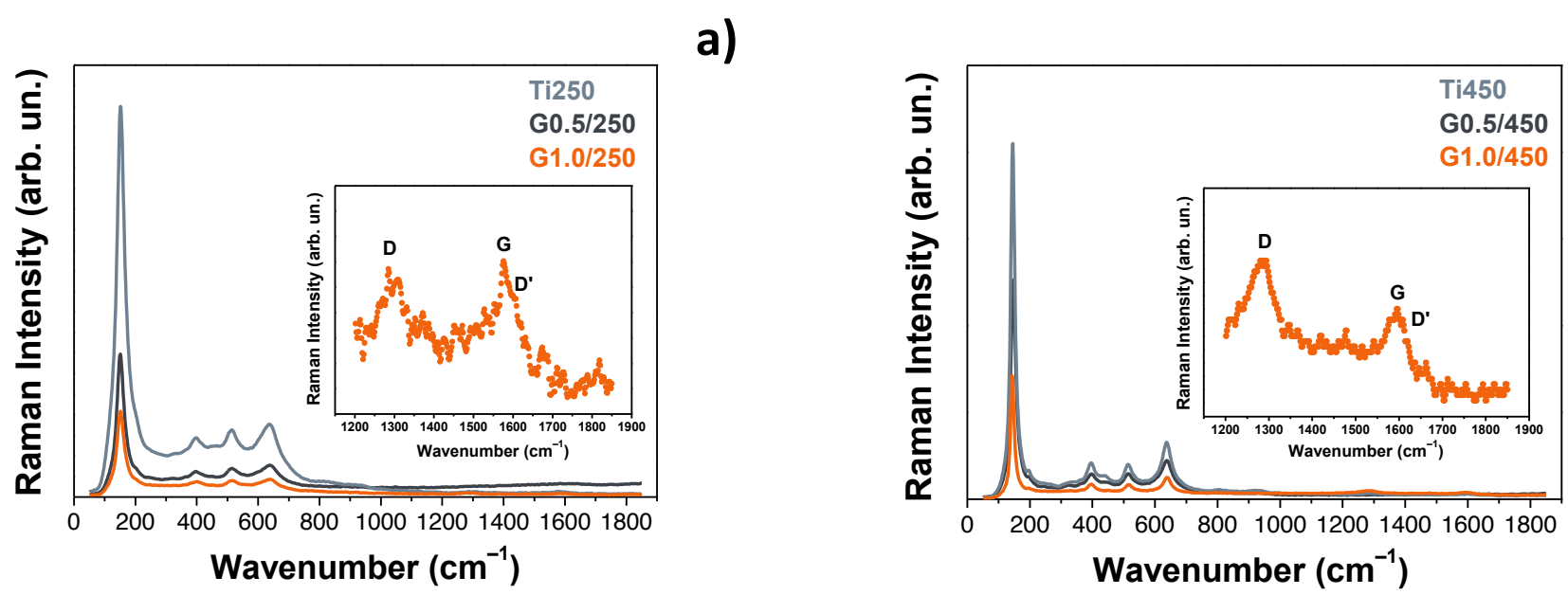

b)

Figure 4. Raman spectra: a) specimens thermally treated at $250{ }^{\circ} \mathrm{C} / 8 \mathrm{~h}$; b) specimens thermally treated at $450{ }^{\circ} \mathrm{C} / 2 \mathrm{~h}$. Insets in a) and b) show the magnified wavenumber region $1200-1850 \mathrm{~cm}^{-1}$, in specimens modified with 1.0 wt\% graphene, to highlight the major graphene bands, $D\left(\sim 1,300 \mathrm{~cm}^{-1}\right), D^{\prime}$ (around $1,610 \mathrm{~cm}^{-1}$ ), and $G$ (approximately at $1,580 \mathrm{~cm}^{-1}$ ).

\section{Functional properties: Gas-phase photocatalytic experiments}

\section{1 de-NO $\mathrm{N}_{x}$ properties}

Solar de- $\mathrm{NO}_{x}$ photocatalytic activity results are shown in Figure $5 \mathrm{a}-\mathrm{d}$. As it is seen in Figure $5 \mathrm{a}, \mathrm{b}$ all of the specimens are able to eliminate the $\mathrm{NO}_{x}$ gases when stimulated by a light simulating the solar radiation (that is with a UV-A component). Specimens thermally treated with the two thermal cycles showed quite similar de- $\mathrm{NO}_{x}$ properties during the total duration of the experiments. This was confirmed by FQEs values too, as reported in Figure $5 \mathrm{c}$. Unmodified specimens thermally treated at $250^{\circ} \mathrm{C} / 8 \mathrm{~h}$ and $450{ }^{\circ} \mathrm{C} / 2 \mathrm{~h}$, after $10 \mathrm{~min}$ irradiation time, had de- $\mathrm{NO}_{x}$ removal rates equal to $6.7 \times 10^{-3}$ and $9.7 \times 10^{-1}$ molecules.photon ${ }^{-1}$, respectively. Upon modification with 0.5 and $1.0 \mathrm{wt} \%$ graphene, in specimens thermally treated at $250{ }^{\circ} \mathrm{C} /$ $2 \mathrm{~h}$, the FQE rates increased to $11.7 \times 10^{-3}$ and $13.3 \times 10^{-3}$ molecules.photon ${ }^{-1}$, respectively. Better $\mathrm{NO}_{x}$ abatements FQE rates were reached when specimens were subjected to a higher thermal treatment, G0.5/450 and G1.0/450, these respectively being: $12.8 \times 10^{-3}$ and $14.0 \times 10^{-3}$ molecules.photon $^{-1}$. To have a better comparison amongst the specimens, these results were compared with the initial (first 2 min of reaction) pseudo-first order kinetic constants, in which are reported the values averaged over three consecutive photocatalytic de- $\mathrm{NO}_{x}$ tests, see Figure $5 \mathrm{~d}$. Indeed, specimens thermally treated at $450{ }^{\circ} \mathrm{C} / 2 \mathrm{~h}$ confirmed themselves to possess a slightly better photocatalytic activity than those treated at $250{ }^{\circ} \mathrm{C} / 8 \mathrm{~h}$. Specimens thermally treated at $450{ }^{\circ} \mathrm{C} / 2 \mathrm{~h}$ have in general a greater size of anatase and rutile crystalline domains ( $c f$ Table S2). This might (partly) justify the slight increase in the de- $\mathrm{NO}_{x}$ properties of those specimens: greater the size, less the defect density in the material (that is: less density of trapping centres), therefore, less probability in the exciton recombination [70]. In any case, specimens hybridised with graphene showed to possess a higher photocatalytic activity. Addition of $1.0 \mathrm{wt} \%$ graphene gave a boost to 
the photocatalytic activity: $\mathbf{G 1 . 0 / 2 5 0}$ and $\mathbf{G 1 . 0 / 4 5 0}$ almost doubled their photocatalytic activity compared to Ti250 and Ti450. Values of the initial $k_{\text {app }}^{\prime}$ for Ti250 and Ti450 were $6.9 \times 10^{-2}$ and $7.1 \times 10^{-2} \mathrm{~min}^{-1}$, respectively. Those of $\mathbf{G 1 . 0 / 2 5 0}$ and G1.0/450: $11.4 \times 10^{-2}$ and $12.7 \times 10^{-2} \mathrm{~min}^{-1}$, respectively. For practical purposes, a photocatalyst should be active over several runs. We have tested the photocatalytic activity of G1.0/450 over five consecutive tests, and this proved to be fully re-usable, see Figure 6 .

Photocatalytic de- $\mathrm{NO}_{x}$ results using the visible white LED lamp are shown in Figure S7. Specimens showed themselves to be photocatalytically active even using a lamp with no UV component - although less active than with the solar lamp. Activity with visible lamp might be justified by the mineralogical composition of the specimens: they are indeed composed of anatase and rutile $\mathrm{TiO}_{2}$ polymorphs (see Table S1). A heterojunction made by a combination of anatase and rutile nanoparticles has been indeed proved to be effective for harvesting visible-light and for granting the material a real visible-light photocatalytic activity [30].

a)
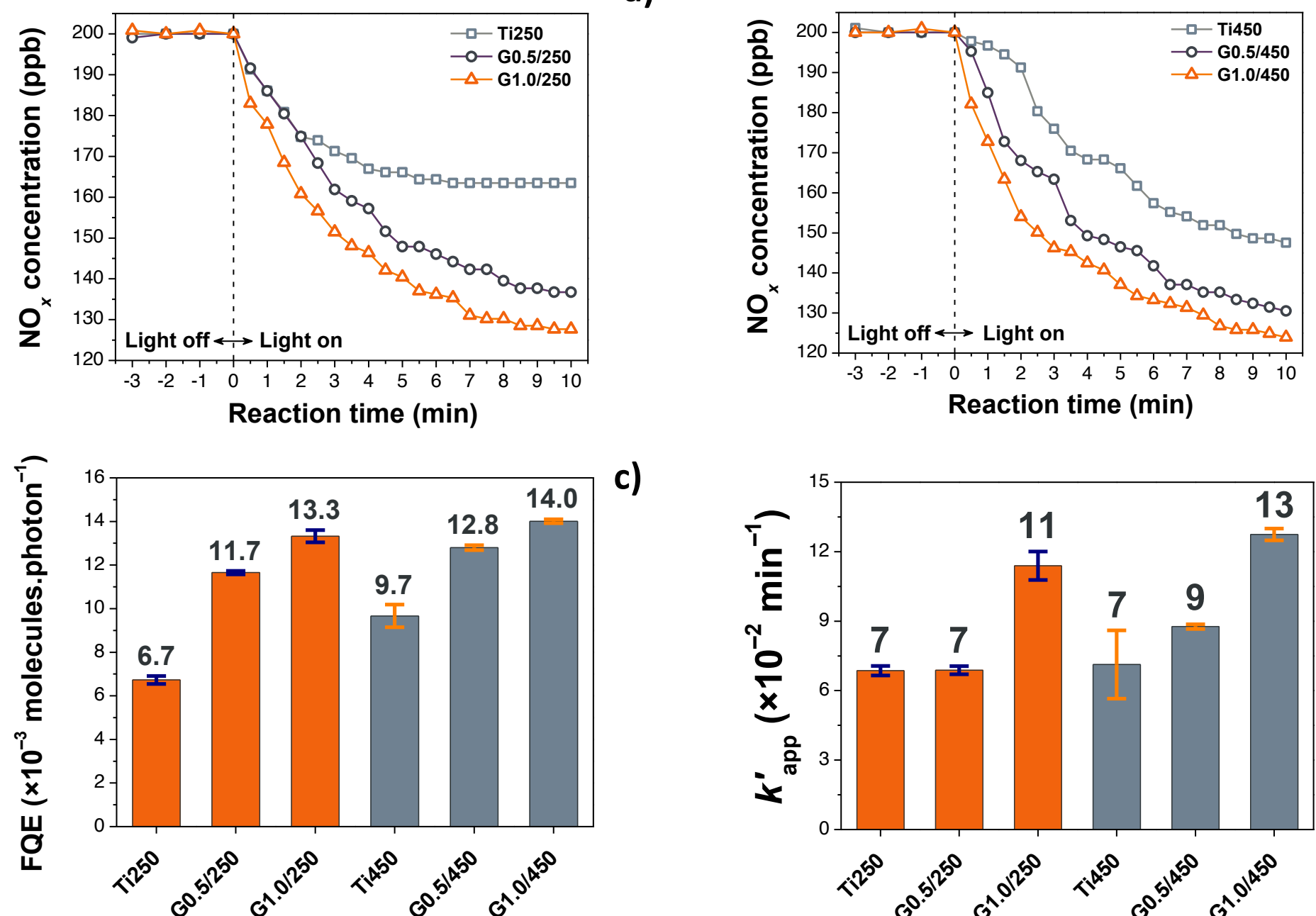

c)

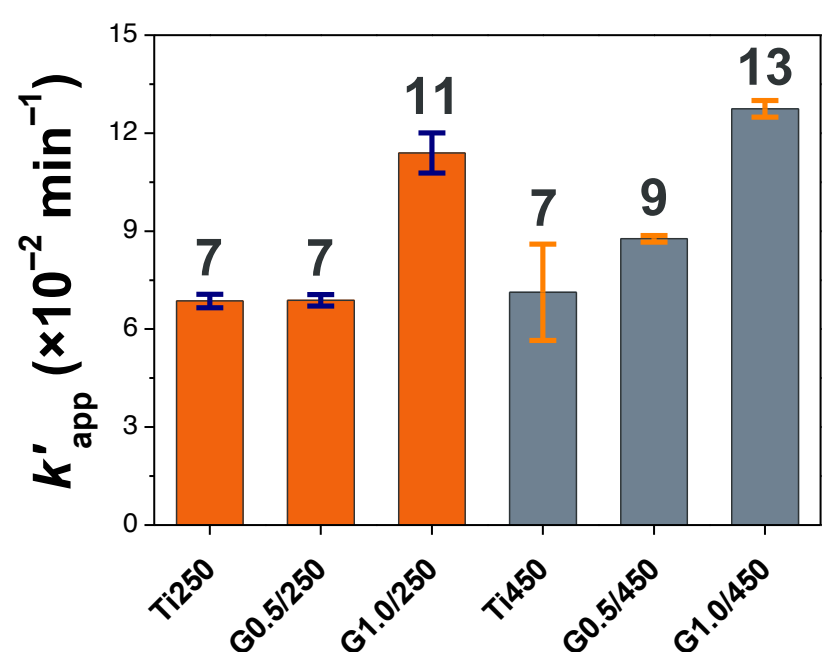

d)

Figure 5. Photocatalytic de- $\mathrm{NO}_{x}$ plots of the samples irradiated with solar lamp. a) Specimens thermally treated at $250{ }^{\circ} \mathrm{C} / 8 \mathrm{~h}$; b) specimens thermally treated at $450{ }^{\circ} \mathrm{C} / 2 \mathrm{~h}$. In a) and b) the initial negative time zone indicates a period of stabilisation of the chamber; positive time indicates that the light has been turned on starting the experiment. c) Histograms depicting FQEs of prepared photocatalysts for $\mathrm{NO}_{x}$ removal, for a total reaction time of $10 \mathrm{~min}$. d) Histograms showing the first $2 \mathrm{~min}$ of reaction pseudo-first order kinetic constants, $k_{\text {app. Reported }}^{\prime}$ values are averaged over three consecutive photocatalytic de- $\mathrm{NO}_{x}$ tests. The error bars represent the standard error over three photocatalytic experiments. 


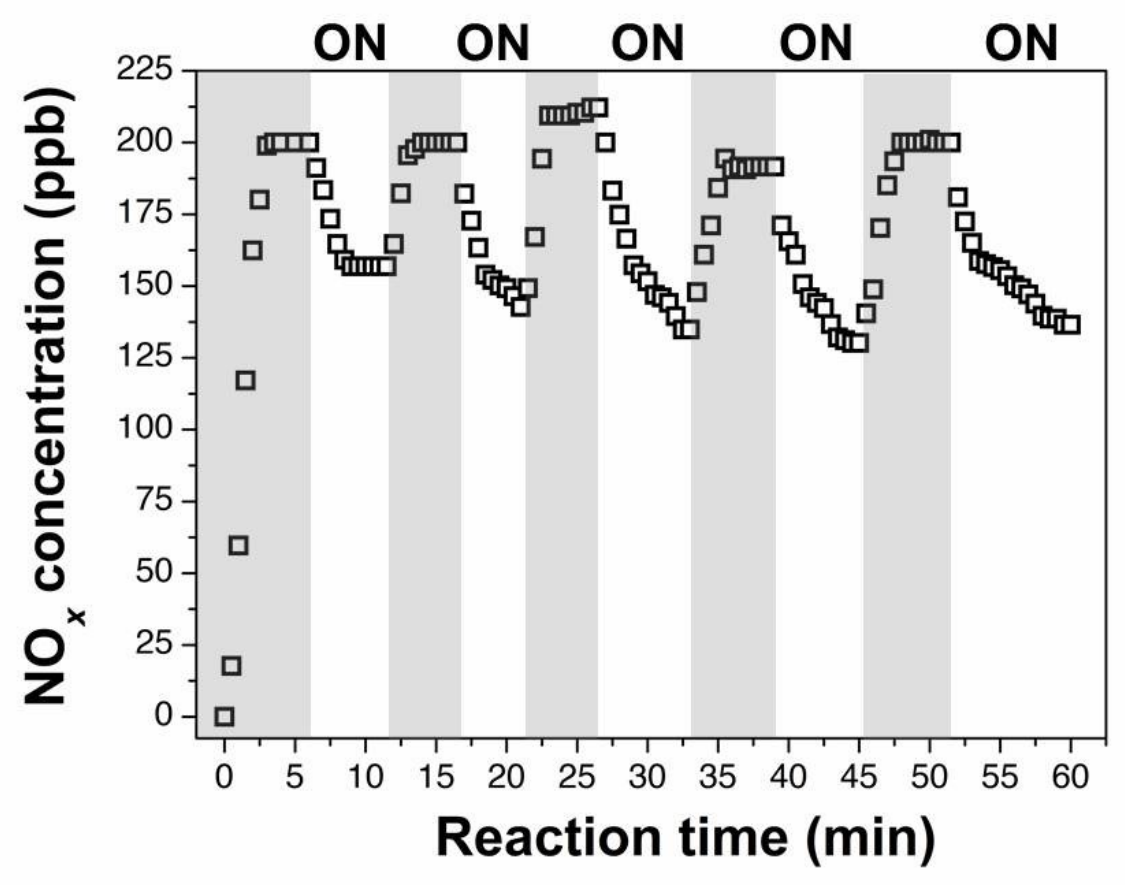

Figure 6. Solar photocatalytic de- $\mathrm{NO}_{x}$ tests (G1.0/450) repeated for five consecutive times. The grey shaded areas represent the time in which the solar lamp was turned off; the white ones the time in which the solar lamp was turned on.

\subsection{VOCs removal}

\subsubsection{Benzene removal}

Solar photocatalytic benzene removal results are reported in Figure $7 a, b$. These are shown as histograms showing FQEs over a total of $5 \mathrm{~h}$ irradiation time, and the first $60 \mathrm{~min}$ of reaction pseudo-first order kinetic constants. These data are pretty much comparable with those obtained with the abatement of nitrogen oxides. That is: all of the samples are photocatalytically active; besides, hybridisation of titania with graphene boosted $\mathrm{TiO}_{2}$ photocatalytic activity. This was approximately two-fold higher for specimens thermally treated at $250{ }^{\circ} \mathrm{C} / 8 \mathrm{~h}$, the overall FQEs values being: $5.4 \times 10^{-8}, 10.3 \times 10^{-8}$, and $10.0 \times 10^{-8}$ molecules.photon $^{-1}$ in Ti250, G0.5/250, and G1.0/250, respectively, of Figure 7a. Increased thermal treatment, led to higher overall FQEs rates: $7.9 \times 10^{-8}, 10.1 \times 10^{-8}$, and $11.0 \times 10^{-8}$ molecules.photon $^{-1}$ in Ti450, G0.5/450, and G1.0/450, over $5 \mathrm{~h}$ irradiation time. However, taking into consideration the initial 60 min of benzene removal, Figure $7 \mathrm{~b}$, specimens with $1.0 \mathrm{wt} \%$ graphene had a photocatalytic activity that was 3 times higher than that of unmodified titania in the set of specimens thermally treated at $250{ }^{\circ} \mathrm{C} / 8 \mathrm{~h}-k_{\text {app }}^{\prime}$ values of Ti250 (G1.0/250) were: $16 \times 10^{-2} \mathrm{~h}^{-1}\left(49 \times 10^{-2} \mathrm{~h}^{-1}\right)$. In case of specimens thermally treated at $450{ }^{\circ} \mathrm{C}$ / $2 \mathrm{~h}$, the $k_{\text {app }}^{\prime}$ values of Ti450 and $\mathbf{G 1 . 0 / 4 5 0}$ were $20 \times 10^{-2} \mathrm{~h}^{-1}$ and $53 \times 10^{-2} \mathrm{~h}^{-1}$, respectively - more than two 
times higher. Likewise de- $\mathrm{NO}_{x}$ tests, $\mathbf{G 1 . 0 / 4 5 0}$ proved itself to be extremely repeatable also in consecutive photocatalytic benzene removal experiments, as depicted in Figure 8.

Visible-light photocatalytic benzene removal results are displayed in Figure S8. Unlike de- $\mathrm{NO}_{x}$ abatement, graphene addition did not increase the visible-light photocatalytic activity of titania in the removal of benzene.
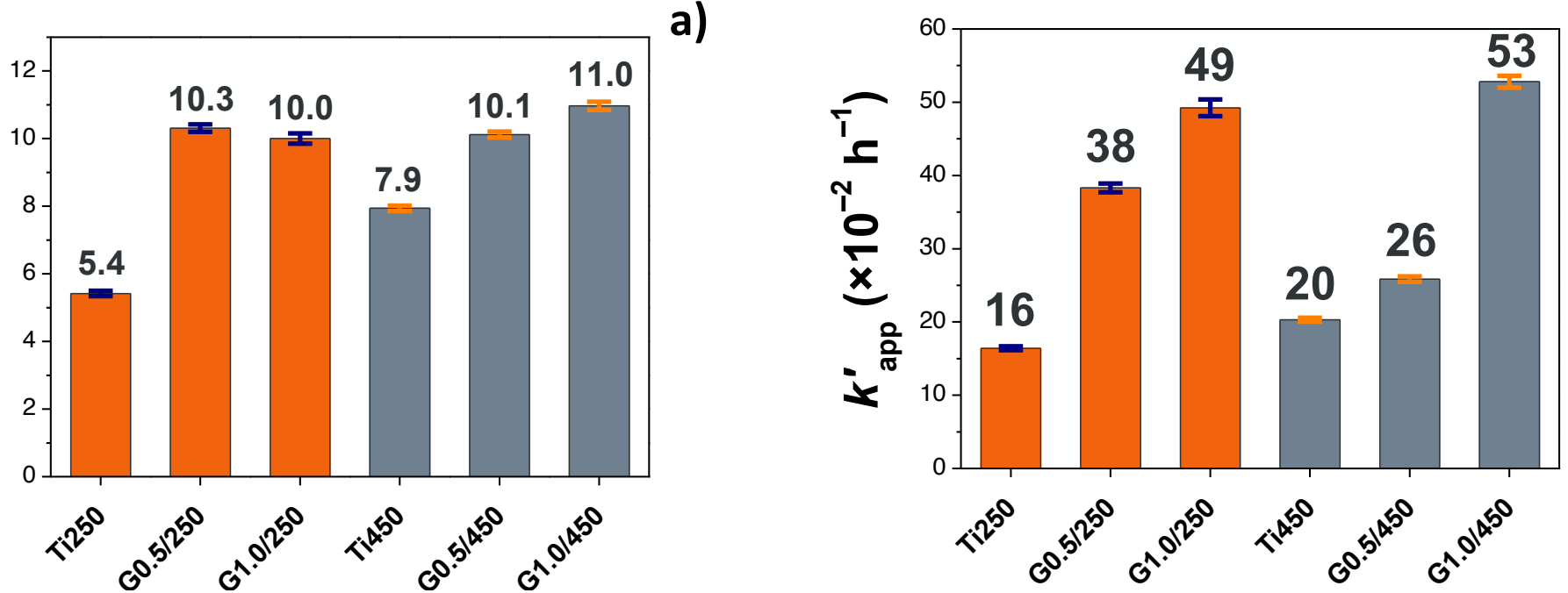

b)

Figure 7. a) Histograms depicting the FQE rates of prepared photocatalysts for benzene removal using the solar lamp, for a total reaction time of 5 h. b) Histograms showing the pseudo-first order kinetic constants (first $1 \mathrm{~h}$ reaction), $k_{\text {app }}^{\prime}$ (solar lamp). Reported values are averaged over three consecutive photocatalytic benzene removal tests. The error bars represent the standard error over three photocatalytic experiments.

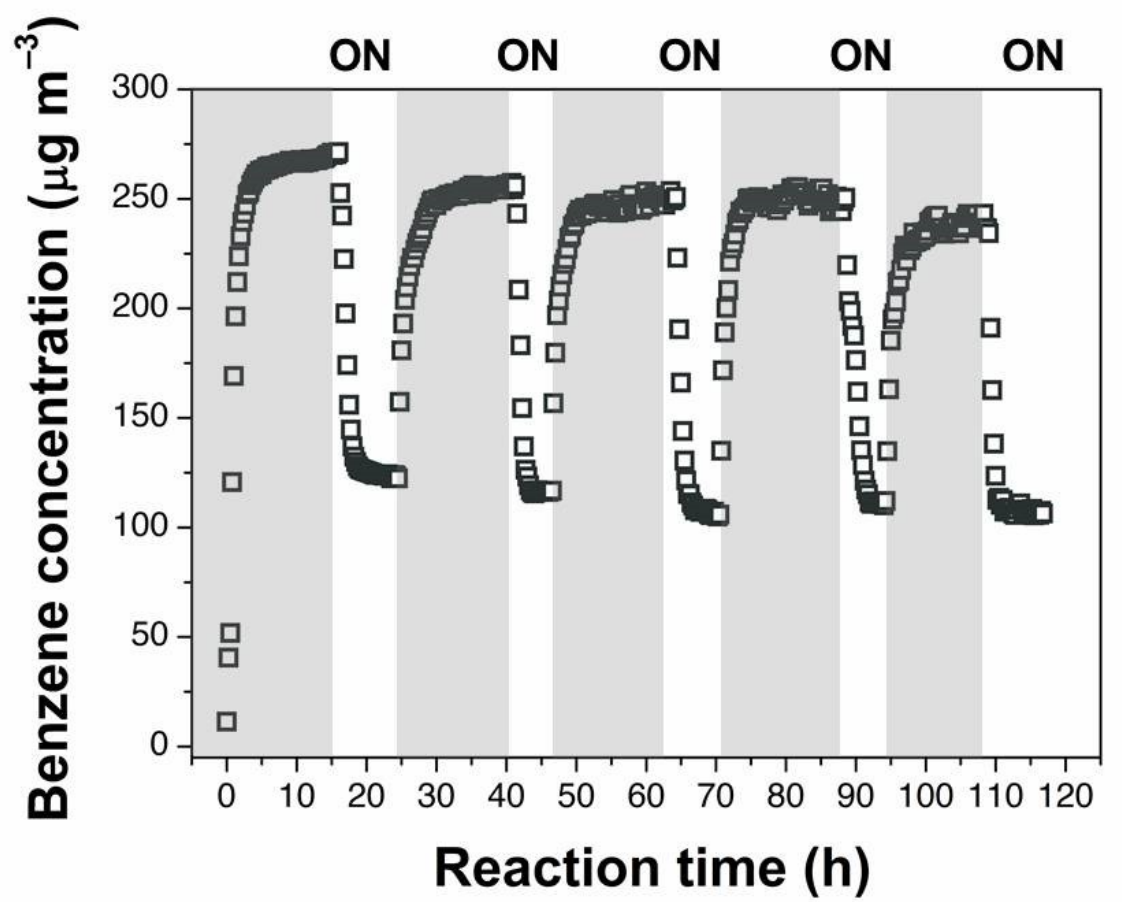

Figure 8. Photocatalytic benzene removal tests (G1.0/450) repeated for five consecutive times. The grey shaded areas represent the time in which the solar lamp was tuned off; the white ones the time in which the solar lamp was turned on. 


\section{$\underline{4.2 .2 \text { Isopropanol oxidation }}$}

UV-Vis photocatalytic activity results of the samples against the removal of IPA, shown as FQE and formation rates of acetone $\left(\mathrm{ppm} . \mathrm{h}^{-1}\right)$, are summarised in Figure 9a,b. Consistent with the data obtained with the $\mathrm{NO}_{x}$ abatement and benzene removal (cf Section 4.1, and Section 4.2.1), addition of graphene to $\mathrm{TiO}_{2}$ aided the photocatalytic assisted IPA oxidation. This is shown by FQEs values (Figure 9a): pure $\mathrm{TiO}_{2}$ at $250{ }^{\circ} \mathrm{C} / 8 \mathrm{~h}$ (Ti250) showed an FQE acetone formation rate of $1.8 \times 10^{-2}$ molecules.photon $^{-1}$. Upon hybridisation with 0.5 and $1.0 \mathrm{wt} \%$ graphene, the FQE acetone formation rate increased to 2.9 and $2.6 \times 10^{-2}$ molecules.photon $^{-1}$ ( $\mathbf{G} \mathbf{0 . 5} / \mathbf{2 5 0}$ and $\mathbf{G 1 . 0 / 2 5 0}$, Figure 9 a). This is also displayed by acetone formation rates of 210, 330, and $295 \mathrm{ppm} . \mathrm{h}^{-1}$ for Ti250, G0.5/250 and G1.0/250, respectively, Figure 9b).

At the higher thermal treatment, addition of 0.5 and $1.0 \mathrm{wt} \%$ graphene were responsible of an acetone formation rate (in terms of FQE) more than the double than that of $\mathrm{TiO}_{2}: 2.2 \times 10^{-2}, 4.4 \times 10^{-2}$, and $4.8 \times 10^{-2}$ molecules. photon $^{-1}$ acetone FQE rate for Ti450, G0.5/450, and G1.0/450, respectively, $c f$ Figure 9a. This correlated well with acetone formation rates values of: 250,510 , and $550 \mathrm{ppm} \cdot \mathrm{h}^{-1}$, respectively (Figure9b).

Contrasting results occurred when visible-light radiation was used, $c f$ Figure S9. At $250{ }^{\circ} \mathrm{C}$, acetone formation rates decreased with the increase of graphene in the system (i.e., the photocatalytic activity was: $\mathbf{G 1 . 0 / 2 5 0}<\mathbf{G 0 . 5 / 2 5 0}<\mathrm{Ti250}$ ). On the contrary, when the specimens were thermally treated at $450{ }^{\circ} \mathrm{C} / 2 \mathrm{~h}$, IPA oxidation had this trend: G1.0/450 > G0.5/450 > Ti450, even though the rise in photocatalytic activity was tiny $\left(18,15\right.$, and $14 \mathrm{ppm} . \mathrm{h}^{-1}$, respectively).

Therefore, results reported here emphasise once again the extreme complexity of photocatalytic air purification processes (using different molecules as pollutant to be removed and different light sources).

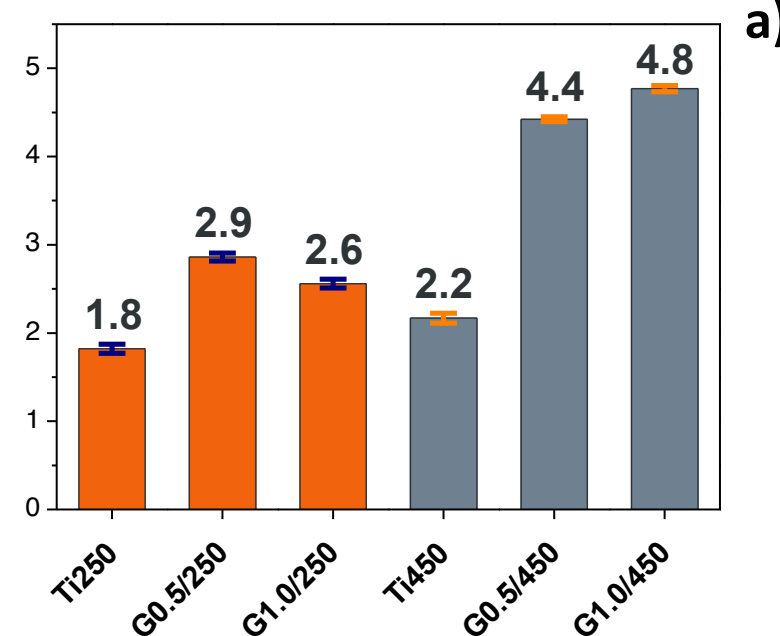

a)

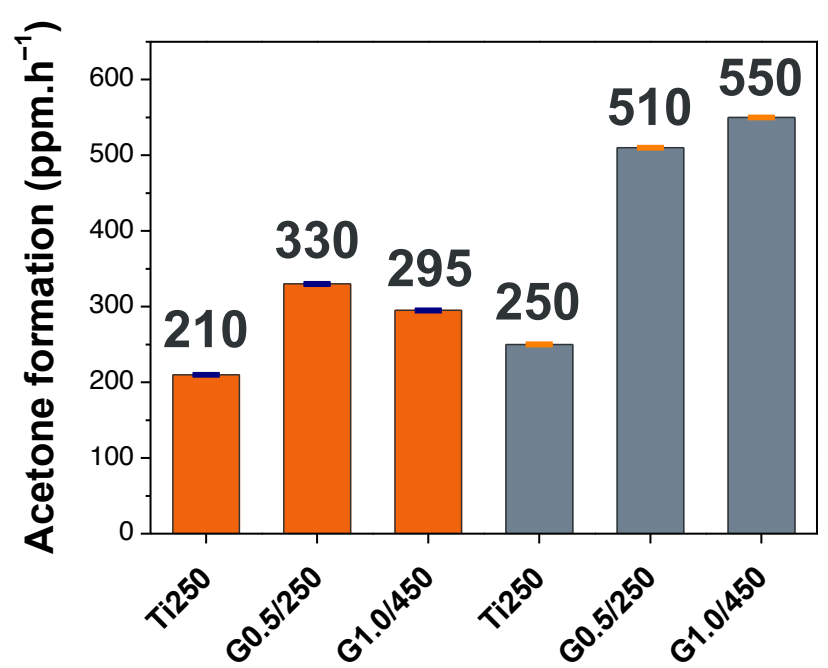

b)

Figure 9. Photocatalytic isopropanol degradation under UV-Vis light exposure, expressed as: a) FQEs of initial acetone formation; b) rate constant of the initial acetone formation. In a) and b), the total irradiation time was set at $1 \mathrm{~h}$. The error bars represent the standard error over three photocatalytic experiments. 


\subsection{EPR spin trapping technique}

The EPR spin trapping technique was applied for the detection of transient paramagnetic species formed upon UVA exposure of powdered photocatalysts impregnated with benzene or IPA containing DMPO spin trap. The analogous DMPO spin-adducts were detected for the photocatalytic systems prepared with Ti450 and $\mathbf{G 0 . 5 / 4 5 0}$ in the presence of IPA or benzene. Figure 10 represents the experimental EPR spectra obtained upon continuous UVA exposure of the powdered photocatalyst G1.0/450 impregnated with IPA/DMPO or benzene/DMPO, along with their simulations. The UVA photoactivation of G1.0/450/IPA/DMPO resulted in the generation of superimposed signals corresponding to the simultaneous production of various DMPO-adducts. The asymmetric six-line signal represents the spinadducts of two carbon-centred radicals with slightly different spin-Hamiltonian parameters, i.e. 'DMPO-CR $\left(a_{\mathrm{N}}=1.453 \mathrm{mT}, a_{\mathrm{H}}{ }^{\beta}=2.178 \mathrm{mT}, g=2.0057\right)$ and ${ }^{\circ} \mathrm{DMPO}-\mathrm{CR}_{2}\left(a_{\mathrm{N}}=1.527 \mathrm{mT}, a_{\mathrm{H}}{ }^{\beta}=2.185 \mathrm{mT}, g=2.0057\right)$ that dominates the EPR spectrum (Figure 10a). Additionally, the spin-adduct of oxygen-centred radical ( $a_{\mathrm{N}}=$ $\left.1.287 \mathrm{mT}, a_{\mathrm{H}}{ }^{\beta}=0.999 \mathrm{mT}, a_{\mathrm{H}}{ }^{\nu}=0.098 \mathrm{mT}, g=2.0057\right)$ was detected as minor spectral component, and was attributed to the trapped $\mathrm{O}_{2}{ }^{--} / \mathrm{HO}_{2}{ }^{\circ}$ radical generated via interaction of photoelectrons with $\mathrm{O}_{2}$ [71]. The formation of oxygen- and carbon-centred radicals detected as the corresponding DMPO-adducts is well compatible with the oxidation of IPA adsorbed on $\mathrm{TiO}_{2}$ surface. The photocatalytic oxidative transformation of IPA is a complex process and acetone as intermediate may be formed by several reaction pathways $[72,73]$. Under those experimental conditions, IPA molecules adsorbed on the photocatalysts' surface reacts with the photogenerated holes forming the primary alkoxy radicals $\left(\mathrm{CH}_{3}\right)_{2} \mathrm{CHO}$. These species rapidly react with other IPA molecules and/or with hydroxyl radicals producing hydroxyalkyl radical $\left[\left(\mathrm{CH}_{3}\right)_{2}{ }^{\circ} \mathrm{C}(\mathrm{OH})\right]$, transformed via consecutive reactions to acetone $[72,73]$
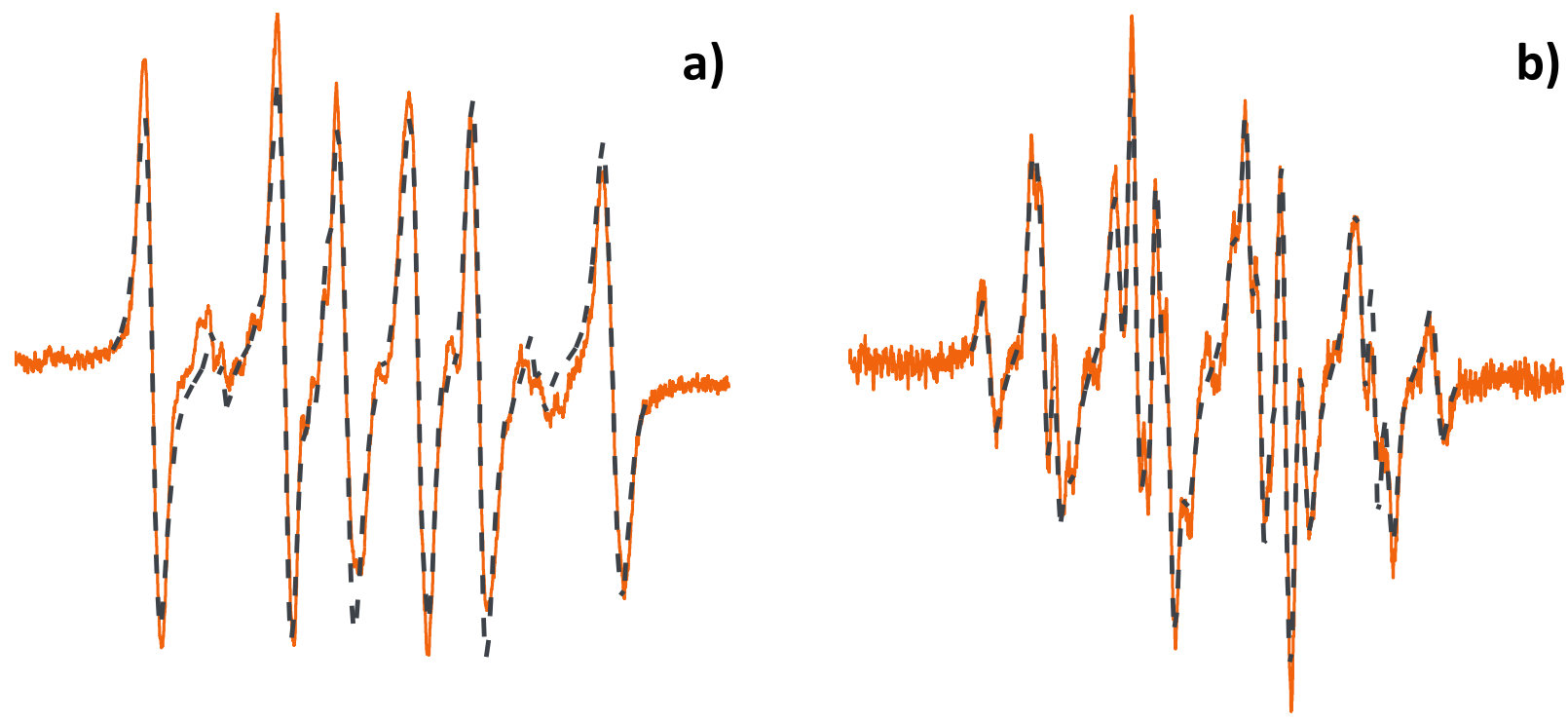

Figure 10. Experimental (orange solid line) and simulated (blue dashed line) EPR spectra (magnetic field sweep width $8.0 \mathrm{mT}$ ) of: (a) IPA, and (b) benzene G1.0/450 impregnated powders in the presence of DMPO spin trapping agent upon LED@365 nm exposure (dose $4.5 \mathrm{~J} . \mathrm{cm}^{-2}$ ). The concentration of oxygen was reduced by the slight stream of argon before exposure. 
Upon continuous LED@365 nm exposure of G1.0/450/benzene/DMPO, the signals of oxygen-centred spinadducts dominate the EPR spectrum (Figure 10b). The crucial twelve-line signal was attributed to the superoxide radical anion added on the DMPO molecule ( DMPO- $\mathrm{O}_{2}{ }^{-} / \mathrm{O}_{2} \mathrm{H}$, spin-Hamiltonian parameters $a_{\mathrm{N}}=$ $\left.1.279 \mathrm{mT}, a_{\mathrm{H}}{ }^{\beta}=1.012 \mathrm{mT}, a_{\mathrm{H}}{ }^{\nu}=0.139 \mathrm{mT}, g=2.0061\right)$. The simulation analysis of the complex experimental EPR spectrum revealed the presence of DMPO-adducts with carbon-centred and alkoxy radicals, originating from benzene molecule [74]. The photocatalytic oxidation of benzene on titania surface is very complex process including photogenerated holes, electrons and reactive oxygen species $[75,76]$. The photogenerated holes may interact with benzene molecule forming benzene radical cation. However, in the presence of $\mathrm{HO}^{-} / \mathrm{H}_{2} \mathrm{O}$ adsorbed on photocatalysts' surface, the holes effectively react with $\mathrm{HO}^{-} / \mathrm{H}_{2} \mathrm{O}$ producing hydroxyl radicals. The addition of $\mathrm{HO}^{\circ}$ to benzene molecule leads to the formation of hydroxy cyclohexadienyl radical, which can enter in consecutive reactions with oxygen, benzene or other species. The photogenerated electrons react with molecular oxygen forming superoxide radical anions. The benzene radical cation may interact also with both $\mathrm{O}_{2}{ }^{--}$and $\mathrm{O}_{2}$ and via transient benzene peroxy radicals, and phenol is formed. The DMPO spin-adducts of peroxy radicals are not stable and may rapidly disproportionate to the detected alkoxy-radical adducts. Alternatively, benzene-based alkoxy radicals formed by the transformation of benzene peroxy radicals, can be directly trapped by DMPO.

\subsection{Mechanistic insight of the photocatalytic activity}

Typically, in a photocatalytic process, those reactions happen at the surface of a semiconductor material:

$\mathrm{TiO}_{2} /$ graphene $+h v \rightarrow \mathrm{e}_{\mathrm{CB}}{ }^{-}+\mathrm{h}_{\mathrm{VB}}{ }^{+}$

$\mathrm{h}_{\mathrm{VB}}{ }^{+}+\mathrm{H}_{2} \mathrm{O}_{(\text {ads })} \rightarrow{ }^{\circ} \mathrm{OH}_{(\mathrm{ads})}+\mathrm{H}^{+}$

$\mathrm{e}_{\mathrm{CB}}^{-}+\mathrm{O}_{2 \text { (ads) }} \rightarrow \mathrm{O}_{2 \text { (ads) }}{ }^{-}$

$\mathrm{e}_{\mathrm{CB}}{ }^{-}+\mathrm{h}_{\mathrm{VB}}{ }^{+} \rightarrow$ energy

It has been shown that graphene addition improves the electron transport in $\mathrm{TiO}_{2} /$ graphene hybrid materials [77], therefore being a support with an added-value for $\mathrm{TiO}_{2}$ based photocatalytic reactions. The photogenerated electrons, from the $\mathrm{TiO}_{2}$ component, are swiftly delivered to the surrounding graphene sheets, in a composite fashion. Graphene sheets behave as a highway for the mobility of such electrons, allowing for an increase in the separation of the photogenerated exciton [78]. This is schematically drawn in Figure 11. 


\section{Potential Vs AVS}

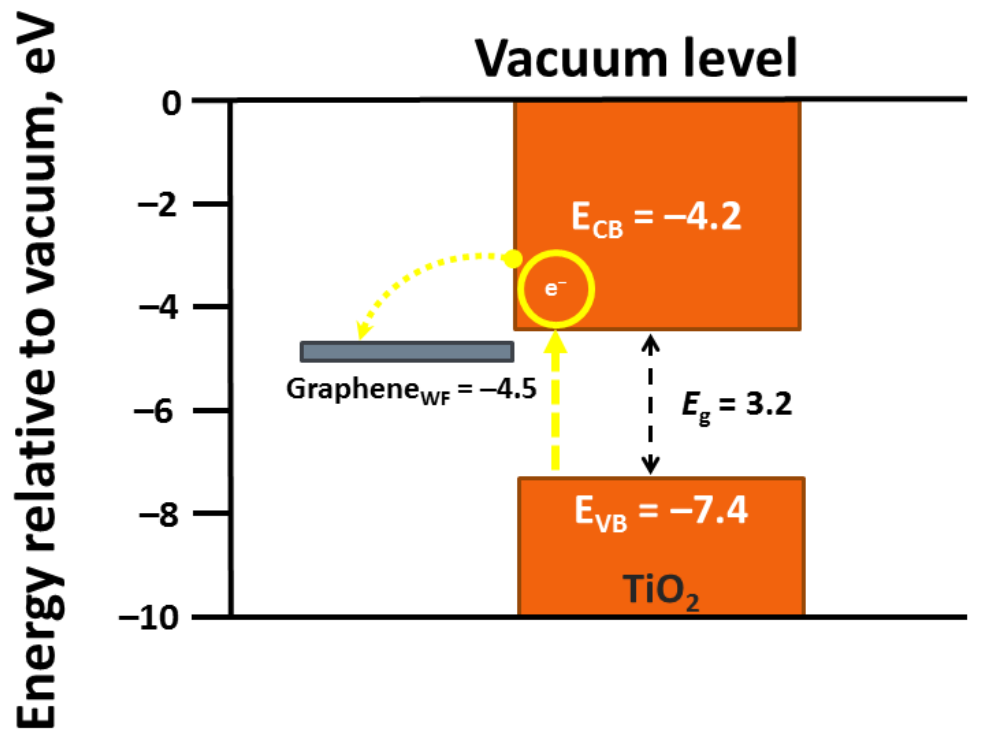

Figure 11. Proposed mechanism for improved spatial charge carrier separation in a graphene$\mathrm{TiO}_{2}$ hybrid material (following to UV-Vis excitation). In the band diagram, relative to the absolute vacuum scale, the dashed yellow arrow shows the electron transferring in titania (from the valence band to the conduction band) due to photocatalysis; the dotted yellow arrow depicts the successive electron transferring from the conduction band of $\mathrm{TiO}_{2}$ to graphene. Energy levels of $\mathrm{TiO}_{2}$ are from specimen $\mathbf{G 1 . 0 / 4 5 0 ~ - ~ e s t i m a t e d ~ a s s u m i n g ~ a ~ d i r e c t ~} E_{\mathrm{g}}$ model, and considering the absolute electronegativity values of the constituent atoms of the material $[79,80]$. The value for the working function (WF) of graphene is from Liang and Ang [81].

Those electrons are then involved in reductive reactions, i.e. the formation of active superoxide ion $\left({ }^{\circ} \mathrm{O}_{2}{ }^{-}\right)$ species with oxygen from the environment (equation 3 ).

According to what reported above, Section 4.3, and looking at Figure 12, it is reasonable assuming $\mathrm{NO}_{x}$ abatement to mainly follow the $\mathrm{NO}$ oxidation path by ${ }^{\circ} \mathrm{O}_{2}{ }^{-}$species:

$$
\begin{aligned}
& \mathrm{NO}+\mathrm{O}_{2(\mathrm{ads})}{ }^{--} \rightarrow \mathrm{NO}_{3}{ }^{-} \\
& \mathrm{NO}_{3}{ }^{-}+\mathrm{H}^{+} \rightarrow \mathrm{HNO}_{3} \\
& \mathrm{HNO}_{3(\mathrm{ads})} \rightarrow \mathrm{HNO}_{3(\mathrm{aq})}
\end{aligned}
$$




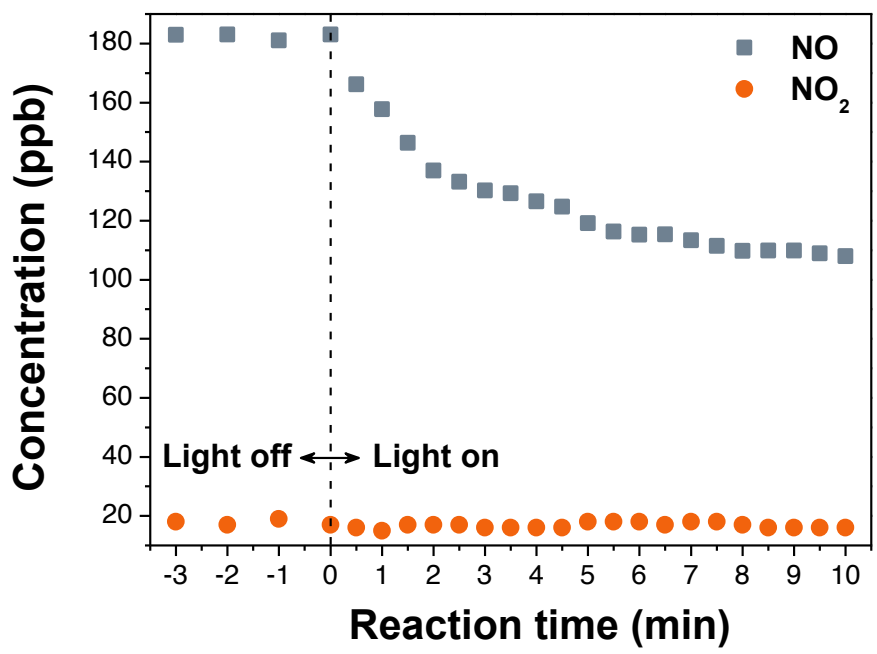

Figure 12. Concentration of $\mathrm{NO}$ and $\mathrm{NO}_{2}$ versus reaction time in $\mathbf{G 1 . 0 / 4 5 0}$.

In the plot displaying the concentration of $\mathrm{NO}$ and $\mathrm{NO}_{2}$ versus reaction time (Figure 12), we assist to an abatement of $\mathrm{NO}$, whilst the concentration of $\mathrm{NO}_{2}$ is virtually stable over the time. The final product of $\mathrm{NO}_{x}$ abatement is $\mathrm{HNO}_{3}$, which can be easily eluted from the catalyst into water [Equation (7)] [82].

A similar hypothesis can be made for IPA degradation. Indeed, Palmisano and colleagues proposed the photocatalytic oxidation of IPA to acetone to follow this path [83]:

$$
\begin{aligned}
& \left.\left(\mathrm{CH}_{3}\right)_{2} \mathrm{CHOH}+\mathrm{O}_{2 \text { (ads) }}\right)^{--} \rightarrow\left(\mathrm{CH}_{3}\right)_{2} \mathrm{CO}+\mathrm{H}_{2} \mathrm{O}+\mathrm{e}^{-} \\
& \left(\mathrm{CH}_{3}\right)_{2} \mathrm{CHOH}+{ }^{\cdot} \mathrm{OH}_{\text {(ads) }} \rightarrow\left(\mathrm{CH}_{3}\right)_{2} \mathrm{C}^{\cdot} \mathrm{OH}+\mathrm{H}_{2} \mathrm{O} \\
& \left(\mathrm{CH}_{3}\right)_{2} \mathrm{C}^{\circ} \mathrm{OH} \rightarrow\left(\mathrm{CH}_{3}\right)_{2} \mathrm{CO}+\mathrm{H}^{+}+\mathrm{e}^{-}
\end{aligned}
$$

The EPR spin trapping technique indeed showed the effective generation of carbon-centred radicals upon exposure, supporting the proposed mechanism.

However, photocatalytic removal of hydrocarbons can be a much more complicated issue. It has been found by Rickard and colleagues that a complete isoprene $\left(\mathrm{C}_{5} \mathrm{H}_{8}\right)$ atmospheric oxidation involved 1,926 different degradation steps, together with the formation of 602 unique intermediate organic species before $\mathrm{CO}_{2}$ and water were eventually formed [84]. Therefore, recognising (qualitatively and quantitatively) all of the intermediated of benzene photocatalytic oxidation really goes out the aims of this work. However, with the available experimental data together with the aid of previous literature, we can speculate about (some of) the degradation products of benzene. The generation of transient radical intermediates upon exposure responsible for the degradation processes of the benzene molecule was confirmed by EPR spin trapping technique. In Figure 13 are reported the gas-chromatograms as extracted (at selected irradiation times) from the gas-analyser during the photocatalytic experiments - specimen G1.0/450. At time zero, just before switching the solar lamp on, benzene is virtually the only compound found (Figure 13a). Lighter and 
heavier degradation compounds than benzene are detected just after $0.5 \mathrm{~h}$ of solar irradiation, together with a decrease in benzene concentration, Figure 13b. Phenol (molar mass, $M=94.11 \mathrm{~g} \cdot \mathrm{mol}^{-1}$ ), 1,4benzoquinone $\left(M=108.095 \mathrm{~g} \cdot \mathrm{mol}^{-1}\right)$, hydroquinone $\left(M=110.11 \mathrm{~g} \cdot \mathrm{mol}^{-1}\right)$, and benzoic acid $(M=122.12$ g. $\mathrm{mol}^{-1}$ ) were detected by means of GC/MS and DRIFT techniques as photocatalytic benzene removal byproducts $[85,86,75,87]$. Those compounds have all a higher molar mass than benzene $\left(M=78.11 \mathrm{~g} \cdot \mathrm{mol}^{-1}\right)$, therefore their presence is reasonable. Ollis and co-authors also found carboxylic acids - acetic and formic acid ( $M=60.052$, and 46.03 g.mol ${ }^{-1}$, respectively) - as intermediates of benzene oxidation [86]. The amounts of benzene and its degradation compound gradually decrease as the exposure time increases (Figure 13c,d). Eventually, after $3 \mathrm{~h}$ irradiation time and ongoing (Figure 13e-h), chromatograms virtually report only benzene and lighter degradation compounds of it. Therefore, from these results, VOCs should not be treated as a single pollutant [88]. Besides, we can postulate that, as proposed by Lichtin and Sadeghi [89], the formation of those intermediates might delay/inhibit the reaction(s) responsible for benzene's mineralisation, therefore competing with benzene, and themselves, in the photocatalytic reaction, hampering the overall kinetic of benzene removal. $\mathrm{TiO}_{2}$ gas-phase photocatalytic oxidation of benzene confirms itself to be a complex matter, having different reaction mechanisms and pathways under different reaction conditions [76]. 


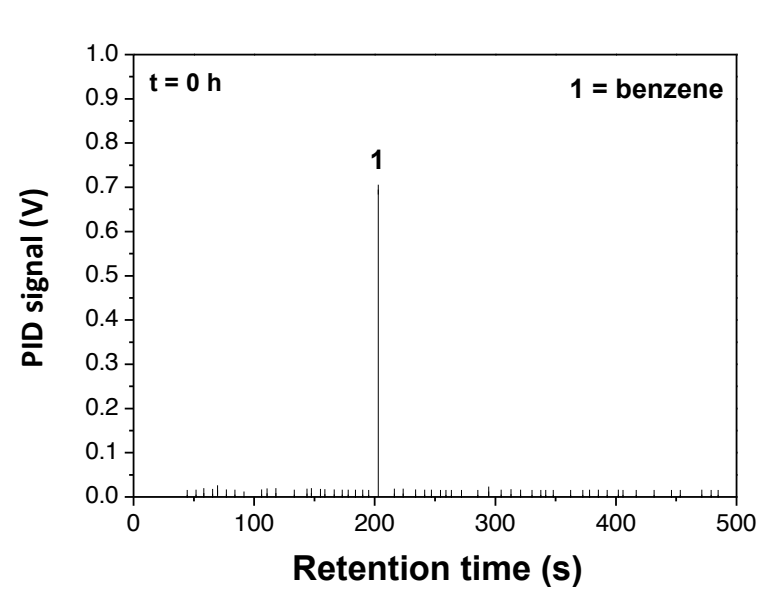

a)

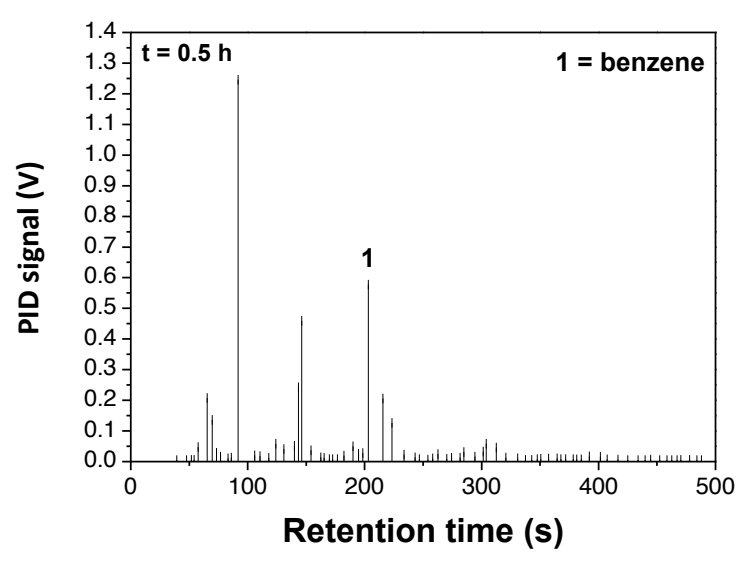

b)

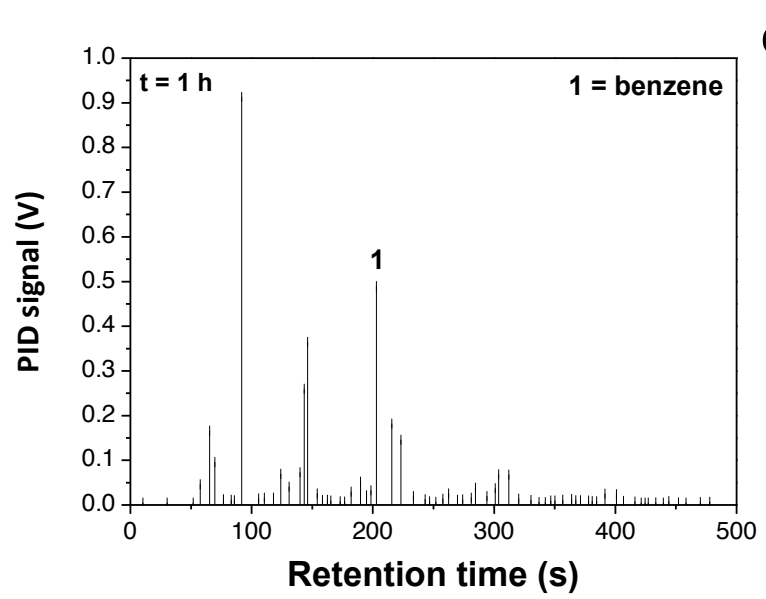

c)

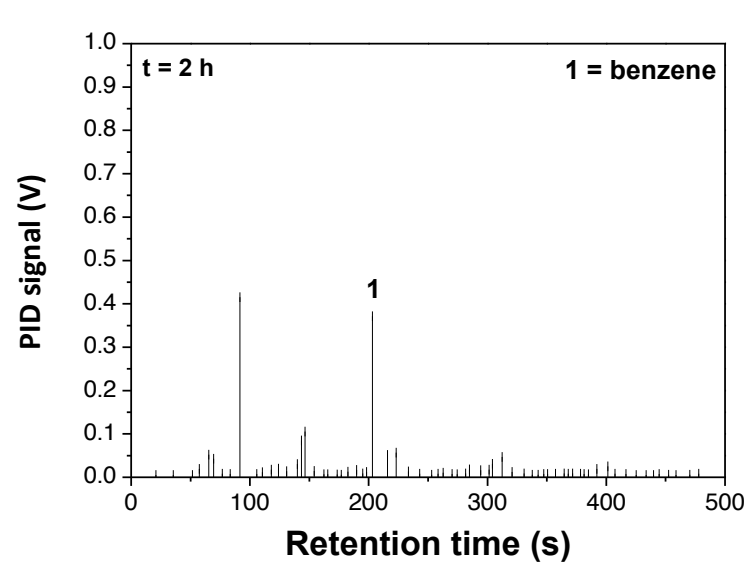

d)
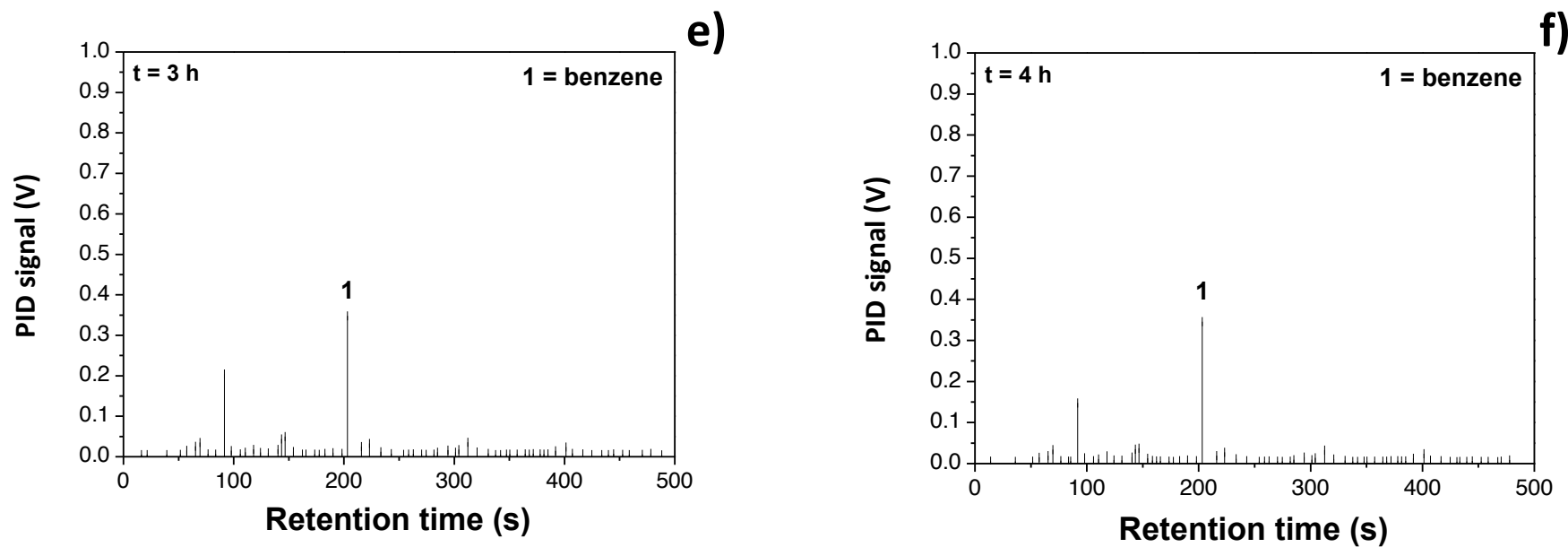

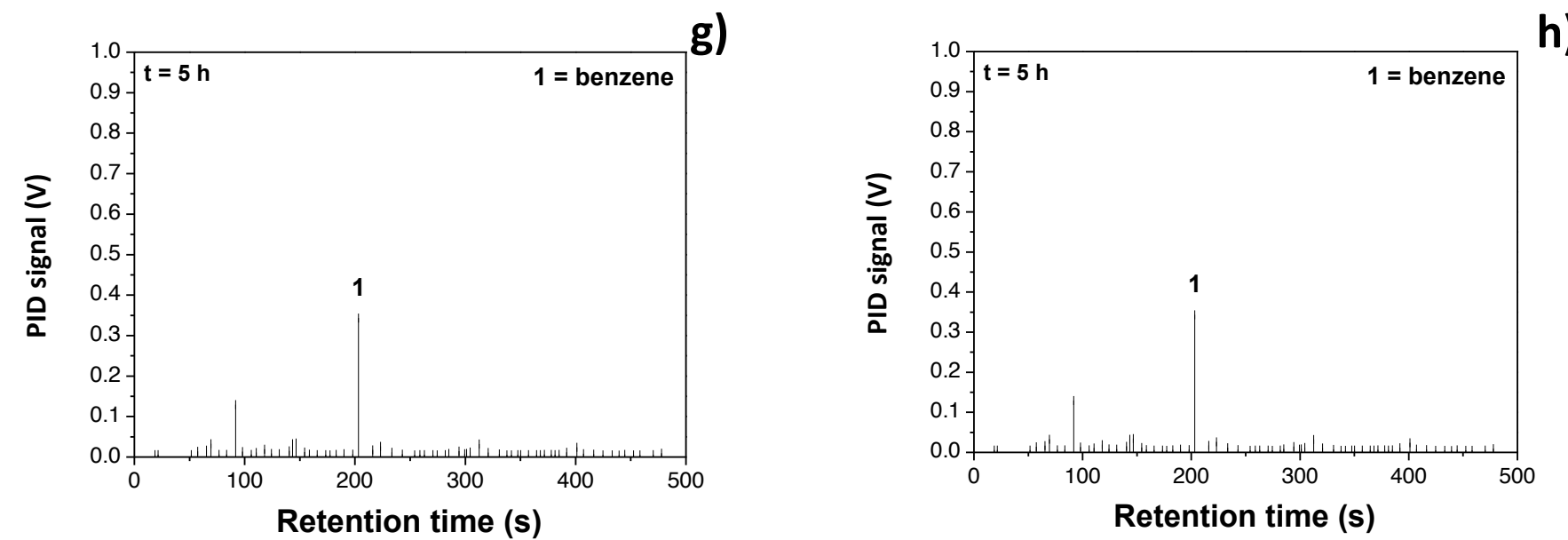

Figure 13. G1.0/450 gas-chromatograms as extracted from the VOC-72M gas analyser at: a) $t=0 ; b) t=0.5 h ; c) t=1$; d) $t=2 h$; e) $t$ $=3 \mathrm{~h} ; \mathrm{f}) \mathrm{t}=4 \mathrm{~h} ; \mathrm{g}) \mathrm{t}=5 \mathrm{~h} ; \mathrm{h}$ ) $\mathrm{t}=6 \mathrm{~h}$ of solar lamp irradiation time. Benzene (symbol 1 in the gas-chromatograms) is at $202 \mathrm{~s}$ retention time.

\section{Conclusions}

Air pollution is cause of adverse health effects worldwide, therefore has to be treated as a global problem. To (partly) tackle this concern, we have synthesised, via a green, clean, and simple sol-gel method, titania/graphene (0.5 and 1.0 wt\% graphene) hybrid nanomaterials. Photocatalytic activity of as-prepared materials was tested against three major pollutants found outdoor: nitrogen oxides (i.e. $\mathrm{NO}+\mathrm{NO}_{2}$ ), and two different kind of volatile organic compounds, namely: benzene and isopropanol. Results showed that the addition of $1.0 \mathrm{wt} \%$ of graphene to $\mathrm{TiO}_{2}$ granted (at least) a two-fold increase in the photocatalytic removal of those gaseous pollutants, being fully recyclable over repeated tests. Indeed, addition of graphene to that semiconducting material acted as a highway for the electron mobility, enhancing the separation of the photogenerated exciton, decreasing their recombination rate. This makes our material an ideal candidate for multi-purpose environmental applications.

\section{Acknowledgements}

This work was partly developed within the scope of the bilateral project between Portugal and the Slovak Republic, FCT/484/15/01/2019/S and in the frame of the project CICECO-Aveiro Institute of Materials, UIDB/50011/2020 \& UIDP/50011/2020, financed by national funds through the Portuguese Foundation for Science and Technology/MCTES. This study was also financially supported by Scientific Grant Agency of the Slovak Republic (VEGA Project 1/0026/18) and Slovak Research and Development Agency under the contract No. SK-PT-2018-0007. David Maria Tobaldi, despite "not so young" and/or "not having given a sufficient level of relevance and impact on the scientific community considering his age", is overly grateful to FCT and to Portuguese national funds (OE), through FCT, I.P., in the scope of the framework contract 
foreseen in the numbers 4, 5 and 6 of the article 23, of the Decree-Law 57/2016, of August 29, changed by Law 57/2017, of July 19. We are very much obliged to Miss Dafne Maria Glaglanon for proof-editing the English of the manuscript.

\section{References}

[1] WHO, Air pollution, (2019). https://www.afro.who.int/health-topics/air-pollution.

[2] J.H. Seinfeld, S.N. Pandis, Atmospheric chemistry and physics: from air pollution to climate change, 3rd edition, Wiley, Hoboken, New Jersey, 2016.

[3] IARC Working Group on the Evaluation of Carcinogenic Risks to Humans, International Agency for Research on Cancer, Outdoor air pollution, 2016. http://www.ncbi.nlm.nih.gov/books/NBK368024/ (accessed October 2, 2019).

[4] B.C. McDonald, J.A. de Gouw, J.B. Gilman, S.H. Jathar, A. Akherati, C.D. Cappa, J.L. Jimenez, J. LeeTaylor, P.L. Hayes, S.A. McKeen, Y.Y. Cui, S.-W. Kim, D.R. Gentner, G. Isaacman-VanWertz, A.H. Goldstein, R.A. Harley, G.J. Frost, J.M. Roberts, T.B. Ryerson, M. Trainer, Volatile chemical products emerging as largest petrochemical source of urban organic emissions, Science. 359 (2018) 760-764. https://doi.org/10.1126/science.aaq0524.

[5] D. Loomis, Y. Grosse, B. Lauby-Secretan, F.E. Ghissassi, V. Bouvard, L. Benbrahim-Tallaa, N. Guha, R. Baan, H. Mattock, K. Straif, The carcinogenicity of outdoor air pollution, The Lancet Oncology. 14 (2013) 1262-1263. https://doi.org/10.1016/S1470-2045(13)70487-X.

[6] S. Weichenthal, T. Olaniyan, T. Christidis, E. Lavigne, M. Hatzopoulou, K. Van Ryswyk, M. Tjepkema, R. Burnett, Within-City Spatial Variations in Ambient Ultrafine Particle Concentrations and Incident Brain Tumors in Adults:, Epidemiology. (2019) 1. https://doi.org/10.1097/EDE.0000000000001137.

[7] D.W. Dockery, C.A. Pope, X. Xu, J.D. Spengler, J.H. Ware, M.E. Fay, B.G. Ferris, F.E. Speizer, An Association between Air Pollution and Mortality in Six U.S. Cities, New England Journal of Medicine. 329 (1993) 1753-1759. https://doi.org/10.1056/NEJM199312093292401.

[8] C.A. Pope, D.W. Dockery, Health Effects of Fine Particulate Air Pollution: Lines that Connect, Journal of the Air \& Waste Management Association. 56 (2006) 709-742. https://doi.org/10.1080/10473289.2006.10464485.

[9] D. Campbell-Lendrum, A. Pruss-Ustun, Climate change, air pollution and noncommunicable diseases, Bull. World Health Organ. 97 (2019) 160-161. https://doi.org/10.2471/BLT.18.224295.

[10] EPA, Particulate Matter (PM) Basics, (2019). https://www.epa.gov/pm-pollution/particulate-matterpm-basics.

[11] J. Ângelo, L. Andrade, L.M. Madeira, A. Mendes, An overview of photocatalysis phenomena applied to NOx abatement, Journal of Environmental Management. 129 (2013) 522-539. https://doi.org/10.1016/j.jenvman.2013.08.006.

[12] C. Guerreiro, A. González Ortiz, F. de Leeuw, M. Viana, A. Colette, European Environment Agency, Air quality in Europe - 2018 report, 2018. https://data.europa.eu/doi/10.2800/777411 (accessed October 7, 2019).

[13] World Health Organization, ed., Air quality guidelines for Europe, 2nd ed, World Health Organization, Regional Office for Europe, Copenhagen, 2000.

[14] L. Benbrahim-Tallaa, R.A. Baan, Y. Grosse, B. Lauby-Secretan, F. El Ghissassi, V. Bouvard, N. Guha, D. Loomis, K. Straif, Carcinogenicity of diesel-engine and gasoline-engine exhausts and some nitroarenes, The Lancet Oncology. 13 (2012) 663-664. https://doi.org/10.1016/S1470-2045(12)70280-2.

[15] Environment and Resources Authority (ERA), Volatile Organic Compounds, (2019). https://era.org.mt/en/Pages/Volatile-Organic-Compounds.aspx.

[16] A.H. Goldstein, I.E. Galbally, Known and Unexplored Organic Constituents in the Earth's Atmosphere, Environ. Sci. Technol. 41 (2007) 1514-1521. https://doi.org/10.1021/es072476p.

[17] R. Atkinson, Atmospheric chemistry of VOCs and NOx, Atmospheric Environment. 34 (2000) 20632101. https://doi.org/10.1016/S1352-2310(99)00460-4. 
[18] B. Sweerts, S. Pfenninger, S. Yang, D. Folini, B. van der Zwaan, M. Wild, Estimation of losses in solar energy production from air pollution in China since 1960 using surface radiation data, Nat Energy. 4 (2019) 657-663. https://doi.org/10.1038/s41560-019-0412-4.

[19] L. Tang, J. Qu, Z. Mi, X. Bo, X. Chang, L.D. Anadon, S. Wang, X. Xue, S. Li, X. Wang, X. Zhao, Substantial emission reductions from Chinese power plants after the introduction of ultra-low emissions standards, Nat Energy. (2019). https://doi.org/10.1038/s41560-019-0468-1.

[20] D. Spasiano, R. Marotta, S. Malato, P. Fernandez-Ibanez, I. Di Somma, Solar photocatalysis: Materials, reactors, some commercial, and pre-industrialized applications. A comprehensive approach, Appl. Catal. B-Environ. 170 (2015) 90-123. https://doi.org/10.1016/j.apcatb.2014.12.050.

[21] S.E. Braslavsky, A.M. Braun, A.E. Cassano, A.V. Emeline, M.I. Litter, L. Palmisano, V.N. Parmon, N. Serpone, Glossary of terms used in photocatalysis and radiation catalysis (IUPAC Recommendations 2011), Pure and Applied Chemistry. 83 (2011). https://doi.org/10.1351/PAC-REC-09-09-36.

[22] A. Fujishima, K. Hashimoto, T. Watanabe, TiO2 photocatalysis: fundamentals and applications, BKC, Tokyo, Japan, 1999.

[23] R. Qian, H. Zong, J. Schneider, G. Zhou, T. Zhao, Y. Li, J. Yang, D.W. Bahnemann, J.H. Pan, Charge carrier trapping, recombination and transfer during TiO2 photocatalysis: An overview, Catalysis Today. 335 (2019) 78-90. https://doi.org/10.1016/j.cattod.2018.10.053.

[24] O. Ola, M.M. Maroto-Valer, Review of material design and reactor engineering on TiO2 photocatalysis for $\mathrm{CO} 2$ reduction, Journal of Photochemistry and Photobiology C: Photochemistry Reviews. 24 (2015) 16-42. https://doi.org/10.1016/j.jphotochemrev.2015.06.001.

[25] K.S. Novoselov, A.K. Geim, I.V. Morozov, D. Jiang, Y. Zhang, Y, S.V. Dubonos, I.V. Grigorieva, A.A. Firsov, Electric Field Effect in Atomically Thin Carbon Films, Science. 306 (2004) 666-669. https://doi.org/10.1126/science.1102896.

[26] A.K. Geim, K.S. Novoselov, The rise of graphene, Nature Materials. 6 (2007) 183-191. https://doi.org/10.1038/nmat1849.

[27] Ol. Bubnova, The graphene times, Nat. Nanotechnol. 14 (2019) 903-903. https://doi.org/10.1038/s41565-019-0561-4.

[28] N. Zhang, M.-Q. Yang, S. Liu, Y. Sun, Y.-J. Xu, Waltzing with the Versatile Platform of Graphene to Synthesize Composite Photocatalysts, Chem. Rev. 115 (2015) 10307-10377. https://doi.org/10.1021/acs.chemrev.5b00267.

[29] Q. Xiang, B. Cheng, J. Yu, Graphene-Based Photocatalysts for Solar-Fuel Generation, Angewandte Chemie International Edition. 54 (2015) 11350-11366. https://doi.org/10.1002/anie.201411096.

[30] D.M. Tobaldi, L. Lajaunie, N. Rozman, A.P.F. Caetano, M.P. Seabra, A. Sever Škapin, R. Arenal, J.A. Labrincha, Impact of the absolute rutile fraction on TiO2 visible-light absorption and visible-lightpromoted photocatalytic activity, Journal of Photochemistry and Photobiology A: Chemistry. 382 (2019) 111940. https://doi.org/10.1016/j.jphotochem.2019.111940.

[31] M.J. Muñoz-Batista, U. Caudillo-Flores, F. Ung-Medina, Ma. del Carmen Chávez-Parga, J.A. Cortés, A. Kubacka, M. Fernández-García, Gas phase 2-propanol degradation using titania photocatalysts: Study of the quantum efficiency, Applied Catalysis B: Environmental. 201 (2017) 400-410. https://doi.org/10.1016/j.apcatb.2016.08.014.

[32] R.J. Slaughter, R.W. Mason, D.M.G. Beasley, J.A. Vale, L.J. Schep, Isopropanol poisoning, Clin. Toxicol. 52 (2014) 470-478. https://doi.org/10.3109/15563650.2014.914527.

[33] W.R.O. for Europe, WHO Guidelines for Indoor Air Quality: Selected Pollutants., World Health Organization, Geneva, 2010.

https://public.ebookcentral.proquest.com/choice/publicfullrecord.aspx?p=1582967 (accessed October 2, 2019).

[34] R. Snyder, C.C. Hedli, An Overview of Benzene Metabolism, Environmental Health Perspectives. 104 (1996) 1165. https://doi.org/10.2307/3433158.

[35] A.C. Larson, R.B. Von Dreele, General Structure Analysis System (GSAS), Los Alamos National Laboratory Report LAUR, 2004.

[36] B.H. Toby, EXPGUI, a graphical user interface for GSAS, Journal of Applied Crystallography. 34 (2001) 210-213. https://doi.org/10.1107/S0021889801002242. 
[37] P. Scardi, M. Leoni, Whole powder pattern modelling, Acta Crystallographica Section A Foundations of Crystallography. 58 (2002) 190-200. https://doi.org/10.1107/S0108767301021298.

[38] M. Leoni, T. Confente, P. Scardi, PM2K: a flexible program implementing Whole Powder Pattern Modelling, Zeitschrift Für Kristallographie Supplements. 23 (2006) 249-254. https://doi.org/10.1524/zksu.2006.suppl_23.249.

[39] P. Stadelmann, JEMS-SAAS, (2014).

[40] T. Sato, Y. Hamada, M. Sumikawa, S. Araki, H. Yamamoto, Solubility of Oxygen in Organic Solvents and Calculation of the Hansen Solubility Parameters of Oxygen, Ind. Eng. Chem. Res. 53 (2014) 1933119337. https://doi.org/10.1021/ie502386t.

[41] S. Stoll, A. Schweiger, EasySpin, a comprehensive software package for spectral simulation and analysis in EPR, Journal of Magnetic Resonance. 178 (2006) 42-55. https://doi.org/10.1016/j.jmr.2005.08.013.

[42] D.M. Tobaldi, L. Lajaunie, M. López Haro, R.A.S. Ferreira, M. Leoni, M.P. Seabra, J.J. Calvino, L.D. Carlos, J.A. Labrincha, Synergy of Neodymium and Copper for Fast and Reversible Visible-light Promoted Photochromism, and Photocatalysis, in $\mathrm{Cu} / \mathrm{Nd}-\mathrm{TiO} 2$ Nanoparticles, ACS Appl. Energy Mater. 2 (2019) 3237-3252. https://doi.org/10.1021/acsaem.9b00084.

[43] W.H.O.R.O. for Europe, Air quality guidelines for Europe, (2000). https://apps.who.int/iris/handle/10665/107335 (accessed February 12, 2019).

[44] European Environment Agency, Nitrogen dioxide - Annual limit values for the protection of human health, (n.d.). https://www.eea.europa.eu/data-and-maps/figures/nitrogen-dioxide-annual-limitvalues-for-the-protection-of-human-health.

[45] M. Karmaoui, L. Lajaunie, D.M. Tobaldi, G. Leonardi, C. Benbayer, R. Arenal, J.A. Labrincha, G. Neri, Modification of anatase using noble-metals ( $\mathrm{Au}, \mathrm{Pt}, \mathrm{Ag}$ ): Toward a nanoheterojunction exhibiting simultaneously photocatalytic activity and plasmonic gas sensing, Applied Catalysis B: Environmental. 218 (2017) 370-384. https://doi.org/10.1016/j.apcatb.2017.06.010.

[46] A. Giampiccolo, D.M. Tobaldi, S.G. Leonardi, B.J. Murdoch, M.P. Seabra, M.P. Ansell, G. Neri, R.J. Ball, Sol gel graphene/TiO2 nanoparticles for the photocatalytic-assisted sensing and abatement of NO2, Applied Catalysis B: Environmental. 243 (2019) 183-194. https://doi.org/10.1016/j.apcatb.2018.10.032.

[47] World Health Organization, WHO. Guidelines for Indoor Air Quality: Selected Pollutants, 2010., WHO Guidelines for Indoor Air Quality: Selected Pollutants. (2010). www.euro.who.int/_data/assets/pdf_file/0009/128169/e94535.pdf.

[48] A. Mills, S. Le Hunte, An overview of semiconductor photocatalysis, Journal of Photochemistry and Photobiology A: Chemistry. 108 (1997) 1-35. https://doi.org/10.1016/S1010-6030(97)00118-4.

[49] R.I. Bickley, G. Munuera, F.S. Stone, Photoadsorption and photocatalysis at rutile surfaces: II. Photocatalytic oxidation of isopropanol, Journal of Catalysis. 31 (1973) 398-407. https://doi.org/10.1016/0021-9517(73)90311-4.

[50] G. Munuera, F. Moreno, J.A. Prieto, Temperature Programmed Desorption of Water Adsorbed on Anatase Surfaces, Zeitschrift Für Physikalische Chemie. 78 (2011) 113-117. https://doi.org/10.1524/zpch.1972.78.3_4.113.

[51] S. Larson, J.A. Widegren, J.L. Falconer, Transient Studies of 2-Propanol Photocatalytic Oxidation on Titania, Journal of Catalysis. 157 (1995) 611-625. https://doi.org/10.1006/jcat.1995.1326.

[52] S. Obregón, G. Colón, Excellent photocatalytic activity of Yb3+, Er3+ co-doped BiVO4 photocatalyst, Applied Catalysis B: Environmental. 152-153 (2014) 328-334. https://doi.org/10.1016/j.apcatb.2014.01.054.

[53] H. Wang, X. Gao, G. Duan, X. Yang, X. Liu, Facile preparation of anatase-brookite-rutile mixed-phase $\mathrm{N}$-doped TiO2 with high visible-light photocatalytic activity, Journal of Environmental Chemical Engineering. 3 (2015) 603-608. https://doi.org/10.1016/j.jece.2015.02.006.

[54] L. Da Vià, C. Recchi, E.O. Gonzalez-Yañez, T.E. Davies, J.A. Lopez-Sanchez, Visible light selective photocatalytic conversion of glucose by TiO2, Applied Catalysis B: Environmental. 202 (2017) 281288. https://doi.org/10.1016/j.apcatb.2016.08.035.

[55] R.D. Shannon, J.A. Pask, Kinetics of the Anatase-Rutile Transformation, Journal of the American Ceramic Society. 48 (1965) 391-398. https://doi.org/10.1111/j.1151-2916.1965.tb14774.x. 
[56] L. Lajaunie, C. Pardanaud, C. Martin, P. Puech, C. Hu, M.J. Biggs, R. Arenal, Advanced spectroscopic analyses on a:C-H materials: Revisiting the EELS characterization and its coupling with multiwavelength Raman spectroscopy, Carbon. 112 (2017) 149-161. https://doi.org/10.1016/j.carbon.2016.10.092.

[57] A.S. Marfunin, Physics of Minerals and Inorganic Materials: An Introduction, Springer-Verlag, Berlin Heidelberg, 1979. //www.springer.com/gp/book/9783642670466 (accessed October 1, 2018).

[58] Q. Huang, S. Tian, D. Zeng, X. Wang, W. Song, Y. Li, W. Xiao, C. Xie, Enhanced Photocatalytic Activity of Chemically Bonded TiO2/Graphene Composites Based on the Effective Interfacial Charge Transfer through the C-Ti Bond, ACS Catal. 3 (2013) 1477-1485. https://doi.org/10.1021/cs400080w.

[59] A. Dolgonos, T.O. Mason, K.R. Poeppelmeier, Direct optical band gap measurement in polycrystalline semiconductors: A critical look at the Tauc method, Journal of Solid State Chemistry. 240 (2016) 4348. https://doi.org/10.1016/j.jssc.2016.05.010.

[60] A.M. Pennington, A.I. Okonmah, D.T. Munoz, G. Tsilomelekis, F.E. Celik, Changes in Polymorph Composition in P25-TiO2 during Pretreatment Analyzed by Differential Diffuse Reflectance Spectral Analysis, J. Phys. Chem. C. 122 (2018) 5093-5104. https://doi.org/10.1021/acs.jpcc.7b10449.

[61] J. Zhang, P. Zhou, J. Liu, J. Yu, New understanding of the difference of photocatalytic activity among anatase, rutile and brookite $\mathrm{TiO}_{2}$, Phys. Chem. Chem. Phys. 16 (2014) 20382-20386. https://doi.org/10.1039/C4CP02201G.

[62] T. Luttrell, S. Halpegamage, J. Tao, A. Kramer, E. Sutter, M. Batzill, Why is anatase a better photocatalyst than rutile? - Model studies on epitaxial TiO2 films, Scientific Reports. 4 (2014) 4043. https://doi.org/10.1038/srep04043.

[63] M.R.F. Silva, M.A.O. Lourenço, D.M. Tobaldi, C.F. da Silva, M.P. Seabra, P. Ferreira, Carbon-modified titanium oxide materials for photocatalytic water and air decontamination, Chemical Engineering Journal. 387 (2020) 124099. https://doi.org/10.1016/j.cej.2020.124099.

[64] N. Serpone, D. Lawless, R. Khairutdinov, Size Effects on the Photophysical Properties of Colloidal Anatase TiO2 Particles: Size Quantization versus Direct Transitions in This Indirect Semiconductor?, The Journal of Physical Chemistry. 99 (1995) 16646-16654. https://doi.org/10.1021/j100045a026.

[65] K. Madhusudan Reddy, S.V. Manorama, A. Ramachandra Reddy, Bandgap studies on anatase titanium dioxide nanoparticles, Materials Chemistry and Physics. 78 (2003) 239-245. https://doi.org/10.1016/S0254-0584(02)00343-7.

[66] K.A. Michalow, D. Logvinovich, A. Weidenkaff, M. Amberg, G. Fortunato, A. Heel, T. Graule, M. Rekas, Synthesis, characterization and electronic structure of nitrogen-doped TiO2 nanopowder, Catalysis Today. 144 (2009) 7-12. https://doi.org/10.1016/j.cattod.2008.12.015.

[67] M. Koelsch, S. Cassaignon, J.F. Guillemoles, J.P. Jolivet, Comparison of optical and electrochemical properties of anatase and brookite TiO2 synthesized by the sol-gel method, Thin Solid Films. 403-404 (2002) 312-319. https://doi.org/10.1016/S0040-6090(01)01509-7.

[68] T. Ohsaka, F. Izumi, Y. Fujiki, Raman spectrum of anatase, TiO2, Journal of Raman Spectroscopy. 7 (1978) 321-324. https://doi.org/10.1002/jrs.1250070606.

[69] A.C. Ferrari, D.M. Basko, Raman spectroscopy as a versatile tool for studying the properties of graphene, Nat Nano. 8 (2013) 235-246. https://doi.org/10.1038/nnano.2013.46.

[70] C. Garlisi, G. Scandura, J. Szlachetko, S. Ahmadi, J. Sa, G. Palmisano, E-beam evaporated TiO2 and CuTiO2 on glass: Performance in the discoloration of methylene blue and 2-propanol oxidation, Applied Catalysis A: General. 526 (2016) 191-199. https://doi.org/10.1016/j.apcata.2016.08.022.

[71] D. Dvoranová, Z. Barbieriková, V. Brezová, Radical Intermediates in Photoinduced Reactions on TiO2 (An EPR Spin Trapping Study), Molecules. 19 (2014) 17279-17304. https://doi.org/10.3390/molecules191117279.

[72] L. Wang, S. Ouyang, B. Ren, J. Ye, D. Wang, Enhanced photocatalytic degradation of 2-propanol over macroporous $\mathrm{GaN} / \mathrm{ZnO}$ solid solution prepared by a novel sol-gel method, APL Materials. 3 (2015) 104414. https://doi.org/10.1063/1.4928702.

[73] W. Xu, D. Raftery, Photocatalytic Oxidation of 2-Propanol on TiO2 Powder and TiO2 Monolayer Catalysts Studied by Solid-State NMR, J. Phys. Chem. B. 105 (2001) 4343-4349. https://doi.org/10.1021/jp004381e. 
[74] C.F. Chignell, A.G. Motten, R.H. Sik, C.E. Parker, K. Reszka, A SPIN TRAPPING STUDY OF THE PHOTOCHEMISTRY OF 5,5-DIMETHYL-1-PYRROLINE N-OXIDE (DMPO), Photochemistry and Photobiology. 59 (1994) 5-11. https://doi.org/10.1111/j.1751-1097.1994.tb04994.x.

[75] J. Zhong, J. Wang, L. Tao, M. Gong, L. Zhimin, Y. Chen, Photocatalytic degradation of gaseous benzene over TiO2/Sr2CeO4: Kinetic model and degradation mechanisms, Journal of Hazardous Materials. 139 (2007) 323-331. https://doi.org/10.1016/j.jhazmat.2006.06.036.

[76] V. Augugliaro, M. Bellardita, V. Loddo, G. Palmisano, L. Palmisano, S. Yurdakal, Overview on oxidation mechanisms of organic compounds by $\mathrm{TiO} 2$ in heterogeneous photocatalysis, Journal of Photochemistry and Photobiology C: Photochemistry Reviews. 13 (2012) 224-245. https://doi.org/10.1016/j.jphotochemrev.2012.04.003.

[77] X. Li, J. Yu, S. Wageh, A.A. Al-Ghamdi, J. Xie, Graphene in Photocatalysis: A Review, Small. 12 (n.d.) 6640-6696. https://doi.org/10.1002/smll.201600382.

[78] A. Trapalis, N. Todorova, T. Giannakopoulou, N. Boukos, T. Speliotis, D. Dimotikali, J. Yu, $\mathrm{TiO} 2 / g r a p h e n e$ composite photocatalysts for NOx removal: A comparison of surfactant-stabilized graphene and reduced graphene oxide, Appl. Catal. B-Environ. 180 (2016) 637-647. https://doi.org/10.1016/j.apcatb.2015.07.009.

[79] R.G. Pearson, Absolute electronegativity and hardness: application to inorganic chemistry, Inorg. Chem. 27 (1988) 734-740. https://doi.org/10.1021/ic00277a030.

[80] Y. Xu, M.A.A. Schoonen, The absolute energy positions of conduction and valence bands of selected semiconducting minerals, American Mineralogist. 85 (2000) 543-556.

[81] S.-J. Liang, L.K. Ang, Electron Thermionic Emission from Graphene and a Thermionic Energy Converter, Phys. Rev. Applied. 3 (2015) 014002. https://doi.org/10.1103/PhysRevApplied.3.014002.

[82] Y. Ohko, Y. Nakamura, A. Fukuda, S. Matsuzawa, K. Takeuchi, Photocatalytic Oxidation of Nitrogen Dioxide with TiO2 Thin Films under Continuous UV-Light Illumination, J. Phys. Chem. C. 112 (2008) 10502-10508. https://doi.org/10.1021/jp802959c.

[83] V. Loddo, G. Marcì, G. Palmisano, S. Yurdakal, M. Brazzoli, L. Garavaglia, L. Palmisano, Extruded expanded polystyrene sheets coated by TiO2 as new photocatalytic materials for foodstuffs packaging, Applied Surface Science. 261 (2012) 783-788. https://doi.org/10.1016/j.apsusc.2012.08.100.

[84] M.E. Jenkin, J.C. Young, A.R. Rickard, The MCM v3.3.1 degradation scheme for isoprene, Atmospheric Chemistry and Physics. 15 (2015) 11433-11459. https://doi.org/10.5194/acp-15-11433-2015.

[85] W.A. Jacoby, D.M. Blake, J.A. Penned, J.E. Boulter, L.M. Vargo, M.C. George, S.K. Dolberg, Heterogeneous Photocatalysis for Control of Volatile Organic Compounds in Indoor Air, Journal of the Air \& Waste Management Association. 46 (1996) 891-898. https://doi.org/10.1080/10473289.1996.10467525.

[86] O. d'Hennezel, P. Pichat, D.F. Ollis, Benzene and toluene gas-phase photocatalytic degradation over $\mathrm{H} 2 \mathrm{O}$ and $\mathrm{HCL}$ pretreated TiO2: by-products and mechanisms, Journal of Photochemistry and Photobiology A: Chemistry. 118 (1998) 197-204. https://doi.org/10.1016/S1010-6030(98)00366-9.

[87] L.-C. Chen, G.-T. Pan, T.C.-K. Yang, T.-W. Chung, C.-M. Huang, In situ DRIFT and kinetic studies of photocatalytic degradation on benzene vapor with visible-light-driven silver vanadates, Journal of Hazardous Materials. 178 (2010) 644-651. https://doi.org/10.1016/j.jhazmat.2010.01.133.

[88] A.C. Lewis, The changing face of urban air pollution, Science. 359 (2018) 744-745. https://doi.org/10.1126/science.aar4925.

[89] N.N. Lichtin, M. Sadeghi, Oxidative photocatalytic degradation of benzene vapor over TiO2, Journal of Photochemistry and Photobiology A: Chemistry. 113 (1998) 81-88. https://doi.org/10.1016/S10106030(97)00327-4. 